Camila Ortiz Prospero Cavalcante Costa

\title{
Avaliação clínico-laboratorial do estado nutricional de adolescentes portadores de doença de Crohn
}

Dissertação apresentada à Faculdade de Medicina da Universidade de São Paulo para obtenção do título de Mestre em Ciências

Programa de Gastroenterologia Clínica

Orientador: Prof.Dr. Flair José Carrilho

São Paulo 
Dados Internacionais de Catalogação na Publicação (CIP)

Preparada pela Biblioteca da

Faculdade de Medicina da Universidade de São Paulo

Creprodução autorizada pelo autor

Costa, Camila Ortiz Prospero Cavalcante

Avaliação clínico-laboratorial do estado nutricional de adolescentes portadores de doença de Crohn / Camila Ortiz Prospero Cavalcante Costa. -- São Paulo, 2011.

Dissertação(mestrado)--Faculdade de Medicina da Universidade de São Paulo.

Programa de Gastroenterologia Clínica.

Orientador: Flair José Carrilho.

Descritores: 1.Doença de Crohn 2.Adolescente 3.Avaliação nutricional 4.Consumo alimentar

USP/FM/DBD-254/11 


\section{Agradecimentos}

Ao Dr Flair José Carrilho por ter me aceito no programa de pós graduação e me auxiliar neste projeto;

À Dra Maraci Rodrigues, pelo carinho, atenção e disponibilidade que me proporcionou ao longo de minha trajetória como pós-graduanda;

Ao Dr Aytan Sipahi, pela ajuda, exemplo de profissional e grandes ensinamentos;

A todos os amigos do laboratório de gastroenterologia (LIM07) pelo afeto, apoio e indispensável colaboração durante esses anos;

Aos pacientes e seus responsáveis, sem os quais não haveria este trabalho;

Aos meus pais por terem sempre me incentivado em todos os caminhos que decidi traçar;

Ao meu marido Marcelo e minha filha Catarina pela paciência, amor, compreensão e carinho. 
Esta dissertação foi elaborada de acordo com as seguintes normas:

Referências: adaptado de International Comitee of Medical Journals Editors (Vancouver)

Universidade de São Paulo. Faculdade de Medicina. Serviço de Biblioteca e Documentação. Guia de apresentação de dissertações, teses e monografias. Elaborado por Anneliese Carneiro da Cunha, Maria Julia de A. L. Freddi, Maria F. Crestana, Marinalva de Souza Aragão, Suely Campos Cardoso, Valéria Vilhena. $2^{a}$ ed. São Paulo: Serviço de Biblioteca e Documentação; 2005.

Abreviaturas dos títulos dos periódicos de acordo com List of Journals Indexed in Index Medicus. 


\section{SUMÁRIO}

Lista de Figuras

Lista de Tabelas

Lista de Abreviaturas e Siglas

Resumo

Summary

1 INTRODUÇÃO ............................................................................

1.1 Particularidades da DC Pediátrica ............................................8

1.2 A Nutrição na DC .....................................................11

1.2.1 Desnutrição Protéico-energética ...............................12

1.3 Composição Corporal ...................................................13

1.4 Déficit de crescimento na DC pediátrica ....................................14

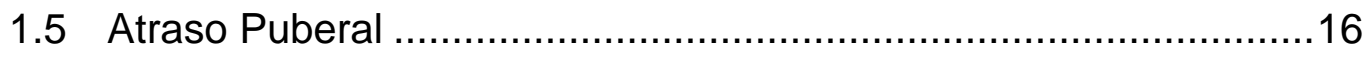

1.6 Deficiência de Micronutrientes .........................................16

1.7 Avaliação Nutricional do paciente com DC pediátrico ...................19

1.8 Avaliação da Composição Corporal do paciente com DC

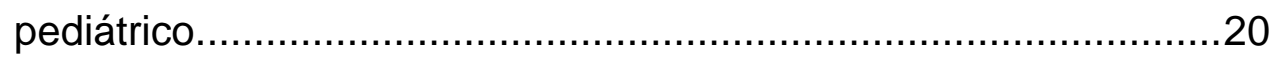

1.9 Consumo Alimentar...................................................... 21

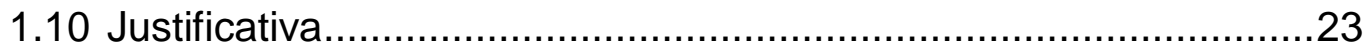

2 OBJETIVO ...................................................................................24

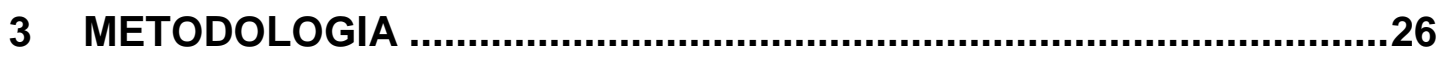

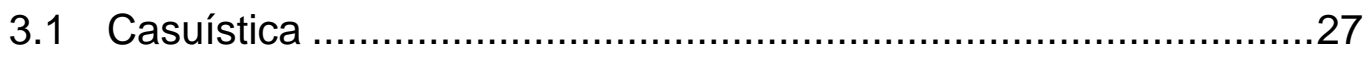

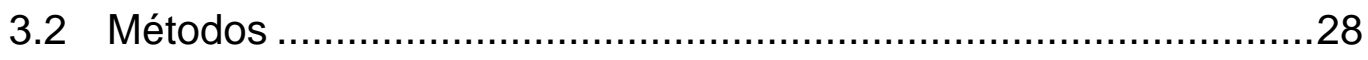

3.2.1 Composição Corporal .................................................28

3.2.2 Consumo Alimentar ............................................. 31

3.2.3 Parâmetros Bioquímicos................................................32

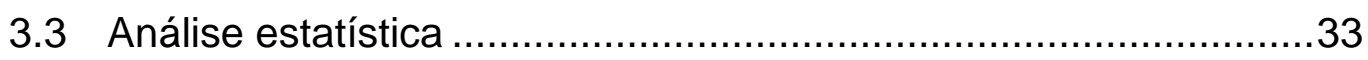




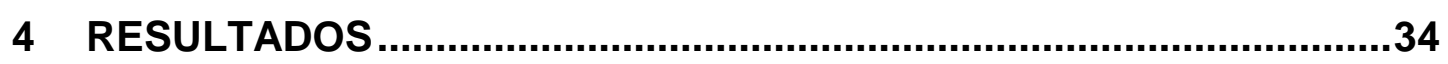

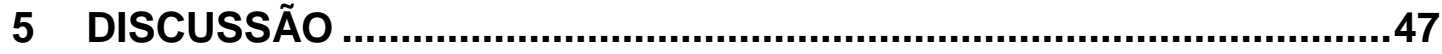

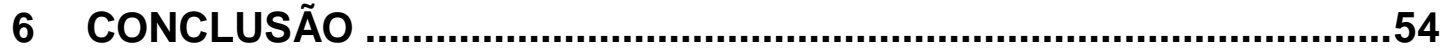

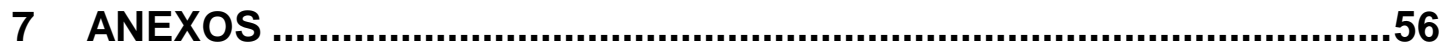

8 REFERÊNCIAS ........................................................................64 


\section{Lista de Figuras}

Figura 1 - Fatores que levam ao retardo do crescimento em crianças com doença de Crohn...

Figura 2 - Percentual de deficiência na ingestão de calorias totais, macronutrientes e fibras nos pacientes com DC em atividade, DC em remissão e grupo controle

Figura 3 - Percentual de deficiência sérica de albumina nos pacientes com DC em atividade, DC em remissão e grupo controle

Figura 4 - Percentual de deficiência na ingestão de minerais nos pacientes com DC em atividade, DC em remissão e grupo controle

Figura 5 - Percentual de deficiência sérica de minerais nos pacientes com DC em atividade, DC em remissão e grupo controle

Figura 6 - Percentual de deficiência na ingestão de vitaminas nos pacientes com DC em atividade, DC em remissão e grupo controle

Figura 7 - Deficiência sérica de vitaminas nos pacientes com DC em atividade, DC em remissão e grupo controle 


\section{Lista de Tabelas}

Tabela 1 - Causas da desnutrição na DC ........................................12

Tabela 2 - Funções dos micronutrientes e a sua importância na DII ..........18

Tabela 3 - Estudos de níveis plasmáticos de micronutrientes em pacientes com DII

Tabela 4 - Estudos de ingestão de micronutrientes em pacientes com DII...22

Tabela 5 - Classificação do estado nutricional (OMS, 2007). ${ }^{104}$ .29

Tabela 6 - Características sociodemográficas dos pacientes com doença de Crohn e do grupo controle.

Tabela 7 - Dados clínicos dos pacientes com doença de Crohn .36

Tabela 8 - Localização e comportamento da doença nos pacientes com doença de Crohn

Tabela 9 - Distribuição dos pacientes com doença de Crohn segundo a utilização de medicamentos atuais

Tabela 10 - Distribuição dos pacientes com doença de Crohn segundo a utilização de medicamentos prévios

Tabela 11 - Avaliação antropométrica dos pacientes com DC em atividade, DC em remissão e do grupo controle 


\section{Lista de Abreviaturas}

$\begin{array}{ll}\text { DC } & \text { Doença de Crohn } \\ \text { DII } & \text { Doença inflamatória intestinal } \\ \text { DRI } & \text { Dietary reference intake } \\ \text { HPLC } & \text { "High-performance liquid chromatography" } \\ \text { IGF-1 } & \text { "Insulin-like growth factor" } \\ \text { IMC } & \text { Índice de massa corporal } \\ \text { NCHS } & \text { "National Center for Health Statistics" } \\ \text { NEE } & \text { Necessidades energéticas estimadas } \\ \text { OMS } & \text { Organização Mundial da Saúde } \\ \text { PCDAI } & \text { "Pediatric Crohn's disease activity index" } \\ \text { PCR } & \text { Proteína C reativa } \\ \text { TGI } & \text { Trato gastrintestinal } \\ \text { VCT } & \text { Valor calórico total }\end{array}$




\section{Resumo}

Costa COPC. Avaliação Clínico-Laboratorial do Estado Nutricional de Adolescentes Portadores de Doença de Crohn [dissertação]. São Paulo: Faculdade de Medicina, Universidade de São Paulo; 2011. 79p.

Introdução: Aproximadamente 25 a $30 \%$ dos pacientes com DC iniciam a doença antes da idade dos 20 anos. O déficit de crescimento é a complicação mais específica da DII pediátrica, causada pela combinação de ingestão calórica inadequada, aumento das perdas calóricas e inflamação ativa persistente da mucosa intestinal. Pacientes com DII comumente sofrem de desnutrição protéico-energética no diagnóstico e com flutuações durante todo o curso da doença. A perda de peso é uma característica comum no paciente com DII recém diagnosticada, particularmente na DC, e acompanha quase todas as recaídas. Aproximadamente $60 \%$ das crianças com DC apresentam perda de peso recente no momento do diagnóstico. Objetivos: verificar o estado nutricional de pacientes portadores de DC na adolescência, através da avaliação da composição corporal, dosagem de macro e micronutrientes e consumo alimentar. Casuística e Métodos: vinte e dois pacientes com DC em atividade (leve ou moderada), vinte e nove com DC em remissão e 35 parentes de $1^{\circ}$ grau desses pacientes de mesma faixa etária (grupo controle) foram selecionados para participar prospectivamente. Antropometria (peso, estatura e índice de massa corporal (IMC) expressos em z escore, bioimpedância e estágio de Tanner), níveis séricos e a ingestão de macro e micronutrientes foram avaliados. Resultados: os adolescentes com DC em atividade seguidos pelo DC em remissão tiveram menor valor de escore $z$ da estatura/idade e IMC para a idade, da massa magra e do estágio pubertário $(p<0,05)$ do que o grupo controle. Os pacientes com DC apresentaram alterações significativas da qualidade da ingestão alimentar, principalmente calorias, proteínas, fibras e micronutrientes, refletindo nas dosagens séricas principalmente das vitaminas $A$ e $E(p<0,05)$. Conclusão: Adolescentes com DC, mesmo quando na fase de atividade da doença leve e inativa, apresentam riscos nutricionais, reforçando a importância da avaliação nutricional.

Descritores: 1.Doença de Crohn 2.Adolescente 3.Avaliação nutricional 4.Consumo alimentar 


\section{Summary}

Costa COPC. Clinical and Laboratory Assessment of Nutritional Status of Adolescents with Crohn's disease [dissertation]. São Paulo: "Faculdade de Medicina, Universidade de São Paulo"; 2011. 79p.

Introduction: About 25 to $30 \%$ of patients with Crohn's disease begin before age 20 years. The growth deficit is the most specific complication of pediatric $C D$, caused by a combination of inadequate energy intake, increased loss of calories and persistent active inflammation of the mucosa intestinal. Patients with IBD often suffer from protein-energy malnutrition in the diagnosis and fluctuations throughout the course of the disease. Weight loss is a common feature in patients with newly diagnosed IBD, particularly in $C D$, and accompanies almost all relapses. Approximately $60 \%$ of children with CD have a recent weight loss at diagnosis Objectives: We aimed to determine the nutritional status of patients with $C D$ in adolescence, through the assessment of body composition, levels of macro and micronutrients and food consumption. Methods: Twenty-two patients with CD activity (mild or moderate), twenty-nine with $C D$ in remission and 35 relatives of a degree of these patients the same age range (control group) were selected to enrolled prospectively. Anthropometry (weight, height and body mass index (BMI) expressed as z score, Tanner stage, and bioimpedance), blood levels and intake of macro and micronutrients were evaluated. Results: Adolescents with $C D$ in activity followed by $C D$ in remission had a lower value of z-score height / age and BMI for age, lean body mass and pubertal stage $(p<0.05)$ than the control group. $C D$ patients showed significant changes in the quality of food intake, especially calories, protein, fiber and micronutrients, mainly reflected in serum levels of vitamins $A$ and $E(p<0.05)$. Conclusion: Adolescents with $C D$, even when the stage of mild activity and inactive, have nutritional risks, reinforcing the importance of nutritional assessment.

Descriptors: 1.Crohn's disease 2.Adolescent 3.Nutritional assessment 4.Food consumption 
1 INTRODUÇÃO 
A doença inflamatória intestinal (DII) pediátrica engloba duas formas fenotípicas bem definidas que afetam o trato gastrointestinal: a doença de Crohn (DC) e a colite ulcerativa (CU), incluindo-se uma terceira apresentação, a colite não determinada (CND), somente quando já foram cumpridas todas as recomendações dos critérios diagnósticos de Porto ${ }^{1}$.

A DC compreende um espectro heterogêneo da DII, de natureza transmural, pois pode atingir toda a parede intestinal, em qualquer segmento do trato gastrointestinal, desde a boca até o ânus, com predileção pela região ileal e ileocecal, de forma descontínua, isto é, áreas acometidas ao lado de áreas aparentemente normais, com a presença típica do granuloma não caseoso, algumas vezes detectado e a possibilidade de algumas complicações, como abscesso, fístulas e estenoses do lúmen intestinal ${ }^{2}$.

A CU compõe a DII na sua forma mais homogênea, caracterizada por inflamação da mucosa do reto (proctite ulcerativa), podendo se estender de forma contínua à mucosa do cólon esquerdo (CU do cólon esquerdo), ou distalmente à flexura hepática (colite extensa) e a forma mais comum na idade pediátrica que abrange toda a mucosa do cólon (pancolite) ${ }^{2,3}$.

O diagnóstico de CND pode ser temporariamente assumido para as crianças e adolescentes somente após se cumprir todas as etapas da investigação sugerida pelos critérios de Porto ${ }^{1}$. Nestes casos, a histologia apesar de identificar inflamação aguda e crônica com mudanças arquiteturais confinadas ao colo e avaliação do delgado normal, há ausência 
de anormalidades específicas, como as encontradas na colite aguda autolimitada, colite linfocítica ou alérgica, mas não foi possível definir os critérios histológicos definitivos de DC ou de $U C^{1,4}$.

Aproximadamente $25 \%$ a $30 \%$ dos pacientes com DC e $20 \%$ dos pacientes com CU iniciam a doença antes da idade dos 20 anos. Embora o pico de início da doença permaneça na final da adolescência, 4\% da DII pediátrica são diagnosticados no início da infância (menos de 5 anos de idade) ${ }^{5}$. Não dispomos de dados epidemiológicos nesta faixa etária no Brasil, exceto um inquérito nacional pediátrico em $2005^{6}$, com um número restrito de estados participantes.

A etiologia da DII é desconhecida, mas sabe-se que é o resultado da desregulação da resposta imune frente a uma flora intestinal normal em hospedeiros geneticamente susceptíveis ${ }^{2}$.

Os fatores genéticos são bem reconhecidos na etiologia da DII, como demonstrado em múltiplos estudos de gêmeos monozigóticos e dizigóticos ${ }^{2}$. Até recentemente, todos os estudos que investigaram os genes candidatos da DII foram realizados em pacientes adultos, embora seja mais comum uma história familiar positiva para DII em crianças e adolescentes ${ }^{7}$. Com o advento de novo método para seleção automática dos grandes genomas (Genome-wide association scanning - GWAS), com a utilização de tecnologia de exibição dos polimorfismos dos nucleotídeos isolados de alta densidade (single nucleotide polymorphism - SNP) foram identificados novos possíveis fatores genéticos associados a patogênese de DII . O primeiro estudo através de GWAS em DII pediátrica foi realizado 
recentemente e revelou duas variantes de risco não previamente relatada em adultos. Os dois novos locci, os genes TNFRSF6B e o PSMG1, foram descobertos avaliando-se mais de 1000 crianças com DII, relacionando-os com o risco aumentado de DC e CU com início na faixa etária pediátrica9 ${ }^{9}$.

Os estudos também mostraram que o gatilho ambiental é outro ponto crítico da etiologia da doença. Existem muitos fatores ambientais que parecem estar associados com a DII. Muitos estudos mostram que o cigarro tem uma clara associação com a DII, com diferentes efeitos na DC e na $C U^{10,11}$, embora ultimamente tenha gerado discusäo. O segundo fator é a flora entérica comensal ${ }^{5}$. Há evidências crescentes, baseadas em modelos experimentais e em informações clínicas, que a microbiota intestinal está associada a DII ${ }^{5}$. Há evidências que reforçam que há efeito benéfico em se tratar a DII com antibióticos. Os experimentos em modelos animais para o desenvolvimento de DII submetidos a ambientes livres de germe não desenvolveram inflamação intestinal, demonstrando a importância da presença da flora entérica ${ }^{5}$. Além disso, podem ocorrer alterações em qualquer nível de interação entre o hospedeiro e o ambiente, incluindo a resposta imune inata e a adaptativa ${ }^{5}$. A descoberta de polimorfismos no gene NOD2 na DC, um gene que controla a sensibilidade das células apresentadoras de antígenos em detectar a presença de bactérias no lúmen intestinal, suporta a hipótese de que uma resposta anormal do hospedeiro à infecção bacteriana parece ser um fator na etiologia da DII .

De acordo com os critérios de Porto $^{1}$, a suspeita clínica de DII na criança ocorre em situação de sintomas persistentes ( $\geq 4$ semanas) ou 
recorrentes ( $\geq 2$ episódios em 6 meses) de dor abdominal, diarréia, sangramento retal e perda de peso. Outros sintomas incluem: febre, retardo do crescimento, desnutrição, náusea e/ou vômitos, sintomas psiquiátricos, artropatia, eritema nodoso, amenorréia secundária e retardo pubertário. O exame físico reforça a possibilidade diagnóstica ao revelar comprometimento do peso e estatura, atraso pubertário, palidez, dedos hipocráticos, ulcerações aftosas e alterações cutâneas, além do exame retovaginal que pode revelar sinais sugestivos da DC, como fístulas (perianais e retovaginais). Devem ser excluídas todas as outras causas de enterites ou colites (Salmonella, Shigella, Yersinia, Campylobacter), avaliação nas fezes para toxinas A e B para Clostridium difficile, Giardia lamblia e Entamoeba histolitica (parasitas, cistos e ovos, ou microscopia direta para trofozoitas), além da possibilidade de imunodeficiência e tuberculose. Lembrar que a identificação do patógeno não exclui necessariamente o diagnóstico de DII, pois um primeiro episódio de DII pode começar após uma infecção entérica. Níveis normais de marcadores inflamatórios nas fezes, como calprotectina ou lactoferrina, denota pouca probabilidade de processo inflamatório ativo no trato gastrointestinal baixo, auxiliando na triagem de investigação invasiva ${ }^{11-18}$. Contudo, a maioria dos estudos avaliou apenas a correlação entre estes marcadores fecais e a inflamação colônica, ainda não sistematicamente explorado nos casos de lesões de delgado de pacientes com $\mathrm{DC}^{11-18}$. Todas as crianças e adolescentes com suspeita de DIl devem ser submetidas a ileocolonoscopia e endoscopia digestiva alta, com biópsias seriadas de cada seguimento do tubo digestivo ${ }^{1}$, para definir os critérios histológicos de DC ou 
$U^{4}$. A indicação de endoscopia digestiva alta na DIl pediátrica foi baseada em estudos retrospectivos e prospectivos mostrando que as biópsias do trato digestivo confirmaram o diagnóstico de DC em 11 a 29\% dos $\operatorname{casos}^{19-22}$. Há a necessidade da avaliação do intestino delgado para auxiliar na diferenciação entre DC e CU e na determinação da extensão da doença ${ }^{1}$. A escolha da técnica para avaliar o intestino delgado nos pacientes com suspeita diagnóstica de DII dependerá da disponibilidade e indicação do método, desde o trânsito intestinal indicado no critério de Porto ${ }^{1}$ até outras alternativas radiológicas, como ressonância magnética ${ }^{23-25}$, com o objetivo de diminuir a exposição radioativa ao paciente ${ }^{26}$. A ressonância magnética tem a sensibilidade de avaliar lesões da DC pediátrica, principalmente fístulas pélvicas e abscessos, sem exposição de radiação ionizante ${ }^{23-25}$. A cápsula endoscópica pode ser considerada na investigação diagnóstica da DC do delgado quando a endoscopia do íleo terminal for normal ou não acessível através desta técnica e outros procedimentos radiológicos não forem conclusivos para o diagnóstico ${ }^{27-29}$. Lembrar que em crianças com DII, há maior risco de impactação da cápsula do que em outras indicações clínicas deste método, além disso, em crianças menores, pode ser necessário o auxílio da endoscopia digestiva alta para a introdução da cápsula endoscópica no duodeno, devido a impossibilidade de sua deglutição espontânea ${ }^{30-32}$.

A classificação mais recente da DII pediátrica é a classificação de Paris $^{3}$ tanto para a DC quanto para a CU, que foi elaborada por um grupo de gastroenterologistas pediátricos a partir da classificação de Montreal $^{33}$, modificada para a faixa etária pediátrica. A justificativa para as adaptações 
foram baseadas nas características fenotípicas únicas da DII pediátrica: a maior extensão da doença, o quadro dinâmico do fenótipo pediátrico, isto é, a mudança da localização da doença ao longo do tempo, características próprias desta faixa etária, não representadas suficientemente na classificação de Montreal. Além disso, a classificação de Montreal não considera a diminuição do crescimento linear e a idade de início da doença é categorizada arbitrariamente ${ }^{3}$.

A gravidade da DC pode ser avaliada através de um índice específico denominado PCDAI (Pediatric Crohn's Disease Activity Index) ${ }^{34}$. Para avaliar a atividade da CU utilizamos o índice denominado PUCAI (Pediatric Ulcerative Colitis Index) ${ }^{35}$. A avaliação da gravidade da doença tem importância terapêutica e prognóstica.

O déficit de crescimento é a complicação mais específica da DII pediátrica, causada pela combinação de ingestão calórica inadequada, aumento das perdas calóricas e inflamação ativa persistente da mucosa intestinal. A eficácia do tratamento medicamentoso e conseqüente remissão clínica é seguida de recuperação do crescimento linear e desenvolvimento pubertário normais. Em contraste, quando não ocorre o crescimento rápido após a detecção do déficit de crescimento ao diagnóstico, ou quando a velocidade de crescimento diminui durante a manutenção do tratamento, significa que há persistência da atividade da doença, exigindo uma terapia mais agressiva e ajuste na ingestão calórica ${ }^{36-38}$.

$\mathrm{Na}$ CU a nutrição enteral ou parenteral não é indicada como tratamento primário, contudo, é essencial a avaliação nutricional e deve ser 
garantido o suporte nutricional sempre que necessário ${ }^{39}$. Em contraste, na DC a nutrição enteral exclusiva e a corticoterapia são efetivas para a indução da remissão da doença, no entanto, a dieta enteral exclusiva tem poucos efeitos colaterais e promove o crescimento adequado quando comparada a corticoterapia. A fórmula enteral elementar não é mais efetiva comparada a fórmula polimérica ${ }^{40}$.

\subsection{Particularidades da DC Pediátrica}

Os estudos epidemiológicos com a população pediátrica mostraram aumento da incidência da DII, principalmente da DC, na última década 41,42,43,44,45,46 . Estudos de prevalência na faixa pediátrica são escassos, mas estima-se a incidência de DC, na década passada, em crianças e adolescentes na Europa de $3(1-8) / 100.000^{40}$ e nos EUA de 4.6/100.000 crianças por ano ${ }^{47}$.

A relação da incidência entre $\mathrm{DC}: \mathrm{CU}$ difere significativamente em crianças (2.8:1) e adultos $(0.85: 1)^{48}$

Com relação à distribuição por sexo, a DC acomete mais o sexo masculino entre as crianças e adolescentes pelo menos até a idade de 14 ou 15 anos, discutindo-se a influência dos hormônios sexuais na patogênese da doença $^{48,49}$. Nesta linha de pesquisa, um grupo de estudo avaliou o polimorfismo da interleucina-6 (IL-6) em pacientes com DC pediátrico e em controles, e demonstraram que o genótipo da IL-6-174 GG predispõe a DC 
em idade precoce, podendo corresponder ao fator de transcrição da IL-6, que é um fator inibidor do estrógeno, favorecendo o nascimento de meninos ${ }^{50}$.

A maioria dos pacientes com DC pediátrica apresenta localização ileocolônica ou doença colônica, comparados com os adultos que apresentam doença no íleo terminal sem envolvimento colônico ${ }^{48}$. A diferença na distribuição da doença pode ser melhor encontrada em crianças menores de 5 anos que apresentam maior envolvimento do intestino grosso isoladamente ou associado com o delgado ${ }^{5}$. Na criança e no adolescente, o íleo terminal está acometido em cerca de 50 a 70\% dos casos e em mais da metade destes há inflamação em segmentos variáveis do cólon, geralmente ascendente ${ }^{40}$. Recentes estudos demonstraram que o fenótipo do início da apresentação clínica da DC em crianças difere dos adultos, com distribuição mais extensa nos dois primeiros anos do diagnóstico em aproximadamente um terço dos pacientes ${ }^{48}$.

O fenótipo da DC pediátrica é predominantemente inflamatório, embora mesmo com o tratamento, aproximadamente 10 a $15 \%$ evoluem com doença estenosante e penetrante ${ }^{48,49}$.

Os sintomas clássicos da DC são dor abdominal, diarréia sem sangue e volumosa nos pacientes com acometimento do delgado, ou com a presença de muco e sangue quando há acometimento do cólon e, nestes casos, pode estar presente o tenesmo, a urgência evacuatória e o despertar noturno para evacuar, além da perda de peso ${ }^{40}$.

Entre as manifestações extraintestinais, características desta faixa etária, destacam-se: o déficit de crescimento, o qual está presente no 
diagnóstico em $10-40 \%$ dos $\operatorname{casos}^{50-52}$, podendo ser o único sintoma da doença ${ }^{51,52}$, sendo importante calcular a velocidade de crescimento nos últimos anos de vida e avaliar o atraso do desenvolvimento puberal. O início do déficit de crescimento é geralmente insidioso e qualquer criança ou adolescente com alterações do crescimento persistente deveria ser avaliado para a possibilidade de DI $^{54,55}$. Induzir a remissão da doença antes do início da puberdade e manutenção da remissão durante os anos de puberdade é crucial para impedir a baixa estatura.

Também pode estar presente a diminuição da densidade mineral óssea (escore-z $<2$ ) na população pediátrica em $25 \%$ dos pacientes ${ }^{40}$.

É importante lembrar que a ausência de sintomas típicos de dor abdominal e diarréia ou sinais de inflamação não excluem o diagnóstico de DC. Em estudo prospectivo em crianças recém diagnosticadas com DC, $21 \%$ delas tinham valores normais dos quatro marcadores da doença: níveis de hemoglobina, contagem de plaquetas, nível de albumina e hemossedimentação ${ }^{56}$.

A combinação do anticorpo anti-Saccharomices cereviciae (ASCA) positivo e o citoplasmático anti-neutrófilo perinuclear ( $p$ ANCA) negativo apresentou sensibilidade de $47 \%$ e especificidade de $97 \%$ para o diagnóstico de $\mathrm{DC}^{57.58}$. Mamula e cols ${ }^{5}$ observaram que nenhuma das crianças com diagnóstico precoce apresentaram ASCA positivo, possivelmente porque é necessário que o indivíduo com permeabilidade intestinal aumentada seja exposto por vários anos ao Saccharomyces cereviciae para produzir níveis de ASCA detectáveis ${ }^{5,59}$. Recentemente, a 
sorologia para a DII se expandiu para sete diferentes testes sorológicos, entre eles: ASCA IgG, ASCA IgA, p-ANCA, anti-OMP C e anti CBir1 IgG, porém não estão adequadamente estudados na pediatria ${ }^{5}$.

Finalmente, a presença de doença crônica na infância e adolescência pode estar associada com alterações psicológicas importantes, com impacto sobre a educação, relacionamento, desenvolvimento psicossocial e aderência a terapia ${ }^{60}$.

Todas estas particularidades da DC pediátrica tornam a avaliação clínico-laboratorial do estado nutricional desses pacientes no diagnóstico e na evolução da doença de fundamental importância clínica ${ }^{1}$.

\subsection{A Nutrição na DC}

Em 2004, a Sociedade Norte Americana de Pediatria, Gastroenterologia, Hepatologia e Nutrição publicou um consenso de suporte nutricional para os pacientes com DII, destacando os principais problemas nutricionais e propondo orientações para a avaliação e o monitoramento do estado nutricional $^{61}$.

A desnutrição pode ocorrer de diversas formas e influenciar os resultados clínicos, a função do sistema imunológico, a barreira mucosa intestinal, os mecanismos antioxidantes, o crescimento, o desenvolvimento ósseo e a qualidade de vida. Múltiplos fatores estão envolvidos na manifestação da desnutrição na DII, descritos na Tabela 1. 
Tabela 1 - Causas da desnutrição na DC

\begin{tabular}{|c|c|}
\hline Fatores & Rarões \\
\hline Ingestão deficiente & $\begin{array}{l}\text { Apetite diminuído } \\
\text { Aversões alimentares por medo de agravamento dos sintomas }\end{array}$ \\
\hline Má-absorção & $\begin{array}{l}\text { Inflamação intestinal } \\
\text { Ressecção intestinal }\end{array}$ \\
\hline Perdas excessivas & $\begin{array}{l}\text { Enteropatia perdedora de proteínas } \\
\text { Sangramento gastrointestinal } \\
\text { Fístula } \\
\text { Diarréia/esteatorréia }\end{array}$ \\
\hline Necessidades aumentadas & $\begin{array}{l}\text { Aumento das necessidades metabólicas } \\
\text { Aumento do turnover da mucosa gstrointestinal } \\
\text { Aumento do consumo de antioxidantes } \\
\text { Alteração lipídica e oxidação muscular } \\
\text { Febre }\end{array}$ \\
\hline $\begin{array}{l}\text { Atividade da doença } \\
\text { Interações droga-nutriente }\end{array}$ & $\begin{array}{l}\text { Aumento das citocinas pró-inflamatórias } \\
\text { Corticoesteróides: inibição do IGF-1 } \\
\text { Corticoesteróides:mineralização óssea deficiente } \\
\text { Corticoesteróides: prejuízo ao metabolismo da gordura e do } \\
\text { músculo } \\
\text { Metotrexate: prejuízo ao metabolismo do folato } \\
\text { Sulfasalazina: prejuízo à absorção do folato }\end{array}$ \\
\hline
\end{tabular}

Adaptado de Wiskin e cols ${ }^{62}$

\subsubsection{Desnutrição Protéico-energética}

Pacientes com DIl comumente sofrem de desnutrição protéicoenergética no diagnóstico e com flutuações durante todo o curso da doença. A perda de peso é uma característica comum no paciente com Dll recém diagnosticado, particularmente na DC, e acompanha o paciente em quase todas as recaídas. Aproximadamente $60 \%$ das crianças com DC e $35 \%$ com CU, apresentam perda de peso recente no momento do diagnóstico ${ }^{63,64,65}$.

A antropometria é afetada em conseqüência a excessiva perda de peso e a desnutrição. Assim, os pacientes com DII, principalmente com DC, apresentam baixo IMC e estão abaixo do peso quando comparados com os valores de referência ${ }^{66-69}$. 


\subsection{Composição Corporal}

As medidas corporais e o IMC devem ser identificados como um índice do estado nutricional e da composição corporal ${ }^{70}$. Apesar do IMC identificar com acuidade a obesidade ${ }^{71}$ e o risco para a desnutrição na população em geral, não tem precisão diagnóstica para distinguir entre gordura e massa magra, necessitando uma avaliação complementar ${ }^{72}$.

Há diversas razões para a composição corporal dos pacientes com DIl diferir das pessoas saudáveis. A inflamação e a secreção de citocinas pró- inflamatórias podem alterar o metabolismo energético, o turnover protéico e a utilização de substrato ${ }^{73}$, além disso o uso de corticosteróides aumenta a gordura corporal e exerce efeitos catabólicos negativos na massa magra $^{74}$. Por outro lado, a atividade física está diminuída nos pacientes com DIl e correlacionados inversamente com a massa gorda ${ }^{69}$.

Há poucos estudos que avaliam a composição corporal em crianças. Entre estes, a massa magra é descrita como sendo significantemente menor do que nos grupos controle ${ }^{75,76,77}$. Sentogo et $\mathrm{al}^{77}$, em estudo transversal, relataram que meninos e meninas apresentaram diminuição de massa magra de 3,5 e 2,9 kg respectivamente, comparados com o grupo controle, e não tiveram menor taxa de gordura. Burnham et $\mathrm{al}^{66}$, em estudo transversal, também encontraram que crianças com DC tinham uma redução de $6 \%$ da massa magra em relação às crianças saudáveis. Não foi encontrado déficit de massa gorda conforme a definição de caquexia. 
Diferenças nas características clínicas e de seleção dos pacientes recém diagnosticados comparados com aqueles com a doença de longa evolução podem explicar algumas discrepâncias encontradas nos estudos adultos e pediátricos ${ }^{66}$. Além disso, devido a particularidade da DC pediátrica, na qual o déficit de crescimento e o atraso puberal são frequentemente observados, é importante uma comparação adequada da composição corporal entre crianças com DC e saudáveis ${ }^{66,67,68,69,78,}$.

\subsection{Déficit de crescimento na DC pediátrica}

O déficit de crescimento linear é comum e pode preceder os sintomas intestinais na DC em crianças e adolescentes ${ }^{77,79,80,81}$.

Os fatores de risco incluem o processo inflamatório, a gravidade, a localização da doença, o estado nutricional, as drogas utilizadas e a genética do paciente ${ }^{79}$.

Este sinal pode estar presente na apresentação clínica em 32 a 88\% dos casos, dependendo da população estudada e do parâmetro estabelecido $^{55,81}$. Cerca de 19 a 37\% dos pacientes com início da DC na idade pediátrica não alcançarão a estatura alvo, baseada na estatura dos pais, em conseqüência do início da doença nesta fase da vida ${ }^{82-83}$.

Dentre as causas para o déficit de crescimento destaca-se a desnutrição protéico-calórica, as citocinas pró inflamatórias, liberadas em resposta a inflamação, que exercem efeito inibitório direto sobre o crescimento e o uso de medicamentos, em especial o corticosteróide ${ }^{61}$. 
O tratamento com corticosteróide contribui no déficit de crescimento, através da supressão central da liberação do hormônio do crescimento, diminuição da transcrição hepática do receptor do hormônio do crescimento, do IGF-1, e da ligação do IGF-1 na cartilagem óssea ${ }^{84,85}$.

Desta forma, para atingir a velocidade de crescimento normal é necessário promover o controle da inflamação da mucosa intestinal, promover a oferta de nutrição adequada e minimizar a exposição ao corticóide ${ }^{84}$.

Para o diagnóstico do déficit de crescimento em adolescentes é recomendado o indicador altura/idade (A/I), que avalia a desnutrição crônica pregressa ou a continuidade desse déficit ${ }^{86}$.

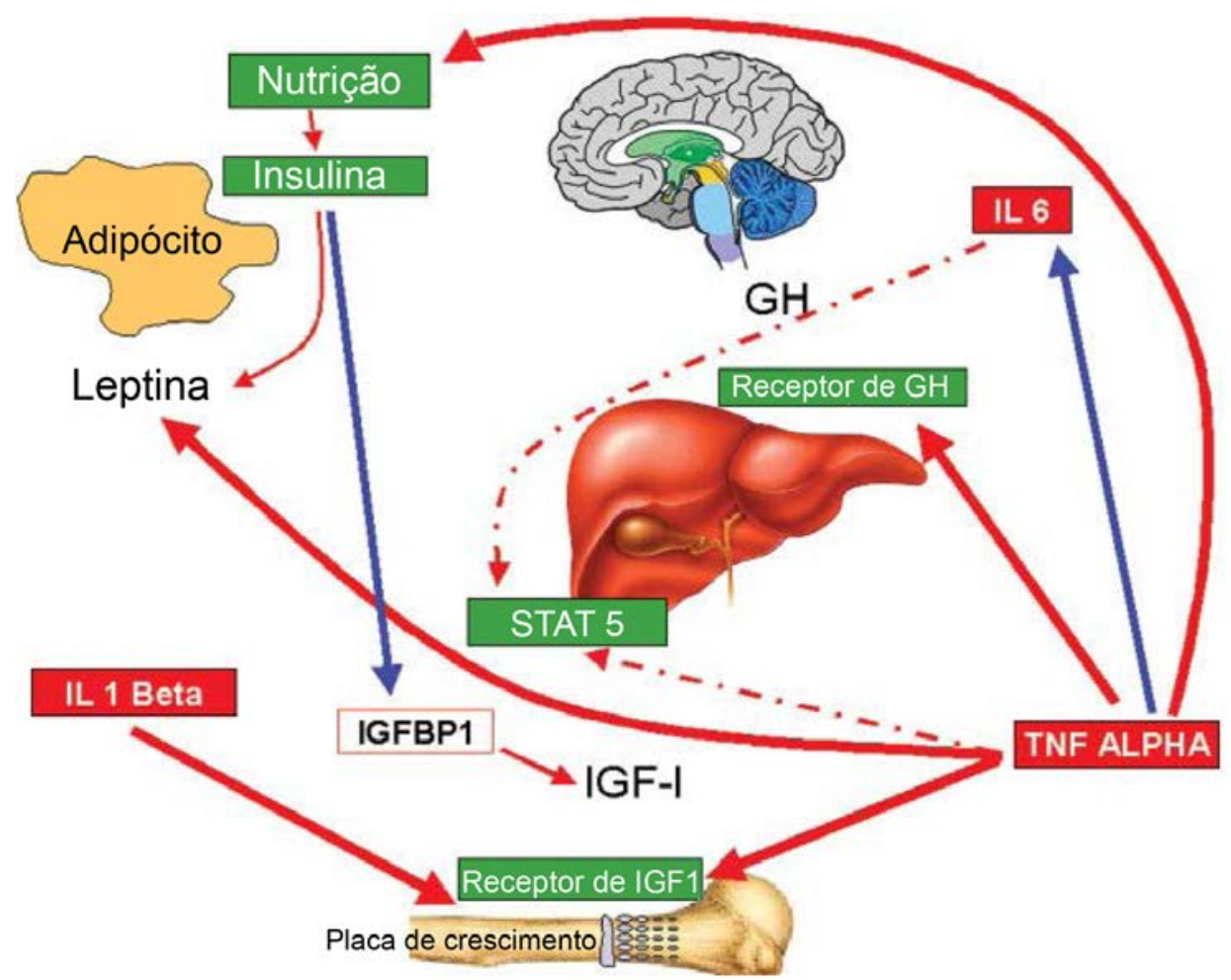

Figura 1 - Fatores que levam ao retardo do crescimento em crianças com doença de Crohn 


\subsection{Atraso Puberal}

O atraso puberal frequentemente é um complicador da DII em pacientes jovens, mais frequente em DC do que $\mathrm{CU}^{66,76,77}$. Em um estudo com pacientes jovens com DC, a menarca ocorreu aos 16 anos ou mais em 73\% das pacientes do sexo feminino cuja doença teve início antes da puberdade. Em contraste, a menarca ocorreu aos 14 anos ou menos em todas as pacientes com CU. O atraso puberal pode influenciar o crescimento linear e a estatura final. Além disso, pode afetar a qualidade de vida e a auto-estima. A desnutrição tem sido considerada a principal causa para o atraso puberal nos pacientes com $\mathrm{DII}^{87}$.

\subsection{Deficiência de Micronutrientes}

Vitaminas, minerais e elementos traço, conhecidos como micronutrientes, são essenciais para o funcionamento normal e desenvolvimento do corpo humano. Na DII, alguns micronutrientes têm importância e função adicional na patogênese e curso clínico da doença, resumidas na Tabela 2. Deficiências de micronutrientes podem influenciar no desfecho clínico e na progressão da DII, afetando o sistema imunológico, a reparação tecidual, o sistema de defesa antioxidante, o crescimento e a mineralização óssea. Um consenso divulgado pela Sociedade Norte 
Americana de Gastroenterologia, Hepatologia e Nutrição Pediátrica sugere como exame de rotina o acompanhamento do nível plasmático de micronutrientes nos pacientes pediátricos com DII ${ }^{61}$.

Há fortes evidências que sugerem que pacientes com DII têm maior estresse oxidativo ${ }^{88,89}$. Isto parece ser resultado de um desbalanço entre o aumento da produção de espécies reativas de oxigênio (EROs) e um mecanismo de defesa antioxidante suprimido, causando prejuízo às macromoléculas biológicas e provavelmente lesões intestinais ${ }^{89-91}$. Wenland et $\mathrm{al}^{89}$ encontraram que a peroxidação lipídica, um marcador da produção de EROs, estava maior nos pacientes com DII comparados com o grupo controle. 
Tabela 2 - Funções dos micronutrientes e a sua importância na DII

\begin{tabular}{|c|c|c|c|}
\hline Micronutrientes & Funções & Deficiëncia & Importäncia na DII \\
\hline Vitamina A & $\begin{array}{l}\text { Pigmento visual na } \\
\text { retina, antioxidante, } \\
\text { desenvolvimento, } \\
\text { diferenciação dos } \\
\text { tecidos }\end{array}$ & $\begin{array}{l}\text { Cegueira noturna, } \\
\text { xeroftalmia, } \\
\text { queratinização }\end{array}$ & $\begin{array}{l}\text { 1. Antioxidante } \\
\text { 2. A eficiência exacerba a CU }\end{array}$ \\
\hline Vitamina D & Balanço do cálcio & $\begin{array}{l}\text { Osteomalácia, } \\
\text { osteoporose }\end{array}$ & $\begin{array}{l}\text { 1. Saúde óssea } \\
\text { 2. Fraturas } \\
\text { 3. Deficiência na DII } \\
\text { 4. Propriedades } \\
\text { antiinflamatórias }\end{array}$ \\
\hline Vitmina $\mathrm{E}$ & Antioxidante & Disfunção neurológica & $\begin{array}{l}\text { 1. Antioxidante } \\
\text { 2. Tratamento da colite }\end{array}$ \\
\hline Äcido fólico & $\begin{array}{l}\text { Síntese de ácido } \\
\text { nucléico }\end{array}$ & Anemia megaloblástica & $\begin{array}{l}\text { 1. Risco de deficiência no uso } \\
\text { de metotrexate e } \\
\text { sulfasalazina } \\
\text { 2. Cäncer colo-retal } \\
\text { 3. Anemia megaloblástica } \\
\text { 4. Hiperhomocisteína }\end{array}$ \\
\hline Vitamina C & $\begin{array}{l}\text { Coenzima na } \\
\text { hidroxilação da prolina e } \\
\text { lisina na síntese do } \\
\text { colágeno, antioxidante, } \\
\text { absorção do ferro }\end{array}$ & $\begin{array}{l}\text { Hemorragia subcutânea, } \\
\text { escorbuto, perda do } \\
\text { esmalte dentário }\end{array}$ & 1. Antioxidante \\
\hline Cálcio (Ca) & $\begin{array}{l}\text { Crescimento e } \\
\text { formação óssea, função } \\
\text { muscular, coagulação } \\
\text { sanguínea }\end{array}$ & $\begin{array}{l}\text { Saúde óssea pobre, } \\
\text { osteoporose, fraturas }\end{array}$ & $\begin{array}{l}\text { 1. Saúde óssea } \\
\text { 2. Fraturas }\end{array}$ \\
\hline Magnésio (Mg) & Estabilização do ATP & $\begin{array}{l}\text { Função muscular } \\
\text { anormal, rompimento do } \\
\text { metabolismo do } \mathrm{Ca}\end{array}$ & 1. Má-absorção \\
\hline Potássio (K) & $\begin{array}{l}\text { Homeostase osmótica, } \\
\text { cofator enzimático no } \\
\text { metabolismo celular e } \\
\text { energético, função } \\
\text { muscular e neural }\end{array}$ & $\begin{array}{l}\text { Disfunção muscular } \\
\text { neural e cardíaca }\end{array}$ & $\begin{array}{l}\text { 1. Distúrbio de eletrólitos na } \\
\text { diarréia severa }\end{array}$ \\
\hline Ferro (Fe) & $\begin{array}{l}\text { Síntese do sangue, } \\
\text { transporte de oxigênio, } \\
\text { produção energética }\end{array}$ & $\begin{array}{l}\text { Anemia, fadiga, } \\
\text { termorregulação } \\
\text { anormal, sistema imune } \\
\text { suprimido, efeitos } \\
\text { adversos no } \\
\text { desenvolvimento } \\
\text { psicomotor e mental }\end{array}$ & $\begin{array}{l}\text { 1. Absorção prejudicada } \\
\text { 2. Anemia } \\
\text { 3. Aumento do estresse } \\
\text { oxidativo }\end{array}$ \\
\hline Zinco (Zn) & $\begin{array}{l}\text { Cofator enzimático, } \\
\text { antioxidante }\end{array}$ & $\begin{array}{l}\text { Retardo do crescimento, } \\
\text { sexual e imaturidade } \\
\text { esquelética, distúrbios } \\
\text { neuropsiquiátricos, } \\
\text { dermatite, alopecia, } \\
\text { diarreia, perda de } \\
\text { apetite }\end{array}$ & $\begin{array}{l}\text { 1. Absorção diminuída } \\
\text { 2. Permeabilidade da mucosa } \\
\text { 3. Propriedades anti- } \\
\text { inflamatórias } \\
\text { 4. Antioxidante }\end{array}$ \\
\hline Cobre (Cu) & $\begin{array}{l}\text { Cofator enzimático, } \\
\text { função no sistema } \\
\text { imune, nervoso e } \\
\text { cardiovascular, saúde } \\
\text { óssea, metabolismo do } \\
\text { ferro, produção } \\
\text { energética, antioxidante }\end{array}$ & $\begin{array}{l}\text { Anemia, neutropenia, } \\
\text { fraturas ósseas, prejuízo } \\
\text { no crescimento, } \\
\text { anormalidades no } \\
\text { metabolismo da glicose } \\
\text { e do colesterol }\end{array}$ & 1. Antioxidante \\
\hline Selënio (Se) & $\begin{array}{l}\text { Cofator enzimático, } \\
\text { antioxidante }\end{array}$ & $\begin{array}{l}\text { Disunção do sistema } \\
\text { imunológico, doença de } \\
\text { Keshan }\end{array}$ & $\begin{array}{l}\text { 1. Deficiëncia na DII } \\
\text { 2. Antioxidante }\end{array}$ \\
\hline
\end{tabular}


Tabela 3 - Estudos de níveis plasmáticos de micronutrientes em pacientes com DII

\begin{tabular}{|c|c|c|c|}
\hline Estudo & População & Micronutrientes & Resultados \\
\hline \multicolumn{4}{|l|}{ Estudos em Adultos } \\
\hline $\begin{array}{l}\text { Hengstermann et al, } \\
2008^{92}\end{array}$ & $\begin{array}{l}132 \text { DII em } \\
\text { remissão, } 35 \\
\text { ativos e } 45 \\
\text { controles }\end{array}$ & $\begin{array}{l}\text { Vitamina C, E, } \\
\text { Carotenóides, Se, Zn } \\
\text { e Cu }\end{array}$ & $\begin{array}{l}\text { Diminuídos em relação ao } \\
\text { controle- vit. C e carotenóides }\end{array}$ \\
\hline Filippi et al $2006^{93}$ & $\begin{array}{l}54 \text { DC em } \\
\text { remissão }\end{array}$ & $\begin{array}{l}\text { Vit. A, C, D, E, B, } \\
\text { folato, niacina, Fe, } \\
\mathrm{Cu}, \mathrm{Ca}, \mathrm{P}, \mathrm{Mg}, \mathrm{Zn}\end{array}$ & $\begin{array}{l}\text { Diminuídos em relação aos } \\
\text { níveis de referência- vit. C, E, } \\
\mathrm{Cu} \text {, niacina, Zn, Fe, folato, }\end{array}$ \\
\hline Wendland et al, $2001^{89}$ & $\begin{array}{l}37 \text { DC e } 37 \\
\text { controles }\end{array}$ & $\begin{array}{l}\text { Vit. C, E e } \\
\text { carotenoides }\end{array}$ & $\begin{array}{l}\text { Diminuidos em relação ao } \\
\text { controle- vit. C e carotenóides }\end{array}$ \\
\hline Geerling et al, $2000^{75}$ & $\begin{array}{l}69 \text { DII e } 69 \\
\text { controles }\end{array}$ & $\begin{array}{l}\text { Vit. A, C, E, B, folato, } \\
\text { Cu, Zn, Mg }\end{array}$ & $\begin{array}{l}\text { Diminuidos em relação ao } \\
\text { controle - Mg, Zn, vit. B }\end{array}$ \\
\hline $\begin{array}{l}\text { Fernandez-Banares et } \\
\text { al, } 1989^{94}\end{array}$ & $\begin{array}{l}23 \text { DIl em } \\
\text { atividade e } 89 \\
\text { controles }\end{array}$ & Vit A, E, B, C, folato & $\begin{array}{l}\text { Diminuidos em relação ao } \\
\text { controle- Vit. A, b, C e folato }\end{array}$ \\
\hline \multicolumn{4}{|l|}{ Estudos em crianças } \\
\hline Bousvaros et al, $1998^{95}$ & $\begin{array}{l}97 \text { DII e } 23 \\
\text { controles }\end{array}$ & Vit. A e E & $\begin{array}{l}\text { Diminuídos em relação aos } \\
\text { níveis de referência- vit. A e E }\end{array}$ \\
\hline $\begin{array}{l}\text { Hoffenberg et al, } \\
1997^{96}\end{array}$ & $\begin{array}{l}24 \text { DII e } 23 \\
\text { controles }\end{array}$ & Vit. A, C, E & $\begin{array}{l}\text { Diminuidos em relação ao } \\
\text { controle- Vit. C }\end{array}$ \\
\hline
\end{tabular}

\subsection{Avaliação Nutricional do paciente com DC pediátrico}

De acordo com a Organização Mundial da Saúde (OMS) ${ }^{86}$, os indicadores antropométricos devem ser utilizados na determinação do estado nutricional e de saúde do indivíduo e da coletividade, sendo importantes no diagnóstico e acompanhamento da situação nutricional e crescimento corporal.

A avaliação nutricional do paciente com DC pediátrico incluem os parâmetros clínicos e laboratoriais ${ }^{62}$. Os parâmetros clínicos nutricionais avaliam a composição corporal como o peso, estatura, estágio de 
desenvolvimento pubertário (estágio de Tanner $^{97}$ ) e avaliação dos compartimentos corpóreos, compostos pela massa magra e de gordura ${ }^{1,98}$. Esta avaliação permite identificar o déficit nutricional, mas não a causa, que na DC pode ocorrer por redução da ingestão, dificuldade de absorção ou por perdas gastrointestinais (Tabela 1 ).

Por outro lado, a avaliação do consumo alimentar do paciente com DC, através do recordatório alimentar de 7 dias $^{104}$, permite identificar e quantificar os déficits específicos da ingestão alimentar e deve ser utilizado de forma complementar para melhor avaliação nutricional do paciente.

No entanto, alguns microelementos não apresentam manifestações clínicas imediatas e específicas e necessitam avaliações laboratoriais. São eles: a albumina sérica, ferro, ferritina, cálcio iônico, vitaminas A, D, E, B12, folato e zinco ${ }^{100}$ e complementam as avaliações clínicas e alimentares.

\subsection{Avaliação da Composição Corporal do paciente com DC pediátrico}

Para a avaliação da composição corporal, a OMS recomenda utilizar o escore $\mathrm{z}$ do IMC/idade (peso $(\mathrm{kg}) /$ altura $\left(\mathrm{m}^{2}\right)$, associado às medidas de espessura da prega cutânea tricipital (PCT) e circunferência do braço (CB), para identificar o compartimento comprometido, através da medida da massa magra e da massa gorda ${ }^{86}$. 
Outra forma de avaliar a composição corporal é através da bioimpedância elétrica. É um método muito utilizado, de fácil aplicação, rápida, não invasiva, barata, com a facilidade de usar um equipamento portátil, o que faz com que seja utilizado em situações e em indivíduos de idades, pesos corporais e estados de saúde diversos. Permite a determinação da massa livre de gordura e da quantidade de água corporal total, tendo por base as diferentes propriedades condutoras e dielétricas dos tecidos biológicos, para correntes de diferentes frequências ${ }^{101}$.

\subsection{Consumo Alimentar}

Em relação ao consumo alimentar, é consenso que, desde o século $X X$, ocorreram mudanças na estrutura familiar, representada principalmente pela inserção da mulher no mercado de trabalho, que influenciou notadamente o padrão alimentar, tornando-se incomuns as refeições com horários definidos e cardápios elaborados para o consumo em família, especialmente nas grandes cidades, onde as atividades são exercidas em

diferentes horários e contextos sociais. $\mathrm{Na}$ atualidade, entre os determinantes do consumo alimentar, também se destaca, em diferentes culturas, a influência da globalização, mais perceptível nas zonas urbanas, onde se observa o consumo exagerado de alimentos industrializados, a partir de influência norte-americana nos costumes de diferentes países ${ }^{102}$. 
$\mathrm{Na}$ adolescência, as práticas alimentares refletem valores aprendidos na família e entre amigos, além da influência da mídia. Nesta fase, o indivíduo sofre mudanças corporais e procura a imagem corporal idealizada, portanto, a alimentação inadequada pode levar a desequilíbrios nutricionais, interferindo no crescimento e no estado de saúde ${ }^{103}$.

Além disso, se esta fase do desenvolvimento pubertário coexistir com a DII, estes adolescentes frequentemente apresentam anorexia, saciedade precoce, dor e desconforto abdominal associados às refeições, limitando ainda mais a ingesta oral e a ingesta calórica total ${ }^{62}$. A Tabela 4 resume alguns estudos sobre a ingestão de micronutrientes em pacientes com DII.

Tabela 4 - Estudos de ingestão de micronutrientes em pacientes com DII.

\begin{tabular}{|c|c|c|c|}
\hline Estudo & População & Design & Resultados \\
\hline \multicolumn{4}{|l|}{ Estudos em Adultos } \\
\hline Aghdassi et al, $2006^{104}$ & $74 \mathrm{DC}$ & $\begin{array}{l}\text { Diário alimentar } \\
\text { de } 7 \text { dias }\end{array}$ & $\begin{array}{l}\text { Diminuídos em relação aos } \\
\text { níveis de referência- vit. A, } \\
C, D, E, B \text {, folato, Ca, Mg, } \\
\text { Fe, Zn. }\end{array}$ \\
\hline Filippi et al, $2006^{93}$ & $\begin{array}{l}54 \text { DC em remissão } \\
\text { e } 25 \text { controle }\end{array}$ & $\begin{array}{l}\text { Diário alimentar } \\
\text { de } 3 \text { dias }\end{array}$ & $\begin{array}{l}\text { Diminuidos em relação ao } \\
\text { controle- Vit. B, C, Mg, } \\
\text { beta caroteno. }\end{array}$ \\
\hline Geerling et al, $1998^{75}$ & $\begin{array}{l}32 \text { DC em remissão } \\
\text { e } 32 \text { controle }\end{array}$ & $\begin{array}{l}\text { Recordatório } \\
\text { alimentar de } 24 \text { hs }\end{array}$ & $\begin{array}{l}\text { Diminuidos em relação ao } \\
\text { controle- Vit. A e P }\end{array}$ \\
\hline \multicolumn{4}{|l|}{ Estudo em crianças } \\
\hline Thomas et al, $1993^{105}$ & 24 DC e 17 controle & $\begin{array}{l}\text { Diário alimentar } \\
\text { de } 5 \text { dias }\end{array}$ & $\begin{array}{l}\text { Diminuidos em relação ao } \\
\text { controle- Vit. C, folato, Fe, } \\
\mathrm{Cu}, \mathrm{Zn}\end{array}$ \\
\hline
\end{tabular}




\subsection{Justificativa}

É comum a presença de alterações nutricionais em pacientes com DC na adolescência, porém, nem sempre pesquisada de maneira adequada e valorizada pelo médico. Sofre influência direta da sociedade onde o paciente está inserido e do tratamento utilizado e, portanto, os dados de outros países não podem ser extrapolados para a realidade brasileira que, somado a escassez de estudos nacionais justificam o presente trabalho. 
2 OBJETIVO 
Este trabalho tem o objetivo de verificar o estado nutricional de um grupo de pacientes adolescentes portadores de DC, através da avaliação da composição corporal, dosagem de macro e micronutrientes e consumo alimentar. 
3 METODOLOGIA 


\subsection{Casuística}

\section{Critérios de Seleção}

Entre janeiro de 2008 e janeiro de 2010, foram convidados a participar da pesquisa pacientes com DC e parentes de $1^{\circ} \mathrm{grau}$ destes pacientes (sem qualquer doença intestinal ou que comprometa o estado nutricional), que preencheram os devidos critérios de inclusão. Os pacientes com DC foram recrutados do Ambulatório do Grupo de Doenças Intestinais do Serviço de Gastroenterologia Clínica do Hospital das Clínicas da Faculdade de Medicina da Universidade de São Paulo (A2MG 500).

O estudo foi encaminhado e aprovado pelo Comitê de Ética em Pesquisa da Universidade de São Paulo. Os pacientes que aceitaram participar do trabalho, voluntariamente assinaram o Termo de Consentimento Livre e Esclarecido (Anexo A).

Os critérios de inclusão foram:

a) Idade entre 12 e 18 anos;

b) Diagnóstico confirmado de acordo com os critérios pediátricos de Porto $^{1}$ para DC com tratamento regular no ambulatório de Gastroenterologia Clínica do Hospital das Clínicas da Faculdade de Medicina da Universidade de São Paulo (HCFMUSP) 
c) O grupo controle foi selecionado por apresentar a mesmas influências culturais (hábitos alimentares) e ambientais (habitar no mesmo município), incluindo a maior adesão por pertencer a própria família.

Os critérios de exclusão foram:

a) portadores de outras doenças como: infecção, câncer, doenças psiquiátricas graves, hipotireoidismo, hipertireoidismo,

b) Uso de corticosteróides nos últimos dois meses;

c) Gravidez;

Para a classificação das características e da gravidade da doença foram utilizados a classificação de Paris $^{3}$ (Anexo B) e o índice de atividade da doença de Crohn Pediátrica (Pediatric Crohn's Disease Activity Index PCDAI) ${ }^{34}$ (Anexo C).

\subsection{Métodos}

\subsubsection{Composição Corporal}

Para a avaliação do peso corporal, os adolescentes utilizaram roupas leves e estavam descalços, sendo assim posicionados sobre uma balança eletrônica do tipo plataforma, com capacidade para $150 \mathrm{Kg}$ e sensibilidade de $100 \mathrm{~g}$. 
Para a aferição da estatura, foi utilizado um estadiômetro, com escala em milímetros. Nesta medição, os indivíduos permaneceram com os pés juntos, calcanhares encostados na parede, em postura ereta, com olhar fixo no horizonte, sem fletir ou estender a cabeça. Em seguida, o avaliador posicionava a barra horizontal do estadiômetro até mantê-la apoiada sobre a cabeça, sendo então efetuada a leitura da altura em centímetros.

Tanto o peso como a estatura foram aferidos em duplicata e pelo mesmo avaliador, sendo adotado o valor médio das duas medidas para o cálculo do Índice de Massa Corporal (IMC), definido como a relação entre o peso em quilogramas e a altura em metros elevada ao quadrado $\left(\mathrm{kg} / \mathrm{m}^{2}\right)$.

Os dados de peso, estatura e IMC foram analisados em percentil do escore-z, utilizando-se o Programa WHO AnthroPlus, que usa como referência os padrões estabelecidos pela Organização Mundial de Saúde (World Health Organization - WHO/OMS) de $2007^{104}$. O cálculo do Índice de Massa Corporal (IMC) foi realizado segundo os critérios de Lohman $(1989)^{105}$. Para a classificação do estado nutricional pelo IMC foram utilizados os padrões estabelecidos pela OMS, de acordo com a idade e sexo (Tabela 5).

Tabela 5 - Classificação do estado nutricional (OMS, 2007). ${ }^{104}$

\begin{tabular}{ll}
\hline SDS escore-Z IMC & Estado nutricional \\
\hline$<-3,0$ & Muito baixo peso \\
\hline$\geq-3,0-<-2,0$ & Baixo peso \\
$\geq-2,0-\leq 2,0$ & Eutrofia \\
$>2,0-\leq 3,0$ & Sobrepeso \\
$>3,0$ & Obesidade \\
\hline
\end{tabular}


Adotamos os valores de escore-z de estatura/idade $<-2,0$ SDS, conforme recomendado pela $\mathrm{OMS}^{104}$, como limite de corte para caracterização da baixa estatura.

A bioimpedância foi realizada no Serviço de Endocrinologia do HCFMUSP. Os participantes do estudo foram orientados a seguir alguns procedimentos prévios, sem os quais os resultados poderiam ser comprometidos: jejum absoluto de 12 horas; não realizar exercícios físicos extenuantes nas 12 horas anteriores ao teste; não ingerir álcool 48 horas antes da realização do teste; não ingerir medicamentos que influenciem o equilíbrio hidroeletrolítico (diuréticos, corticosteroides, entre outros) a menos de 7 dias do teste; retirar brincos, anéis, relógios e objetos metálicos no momento da realização do teste; e urinar pelo menos 30 minutos antes da realização do teste 101,102 $^{10}$

A avaliação da maturação sexual foi realizada por meio da autoavaliação e utilizou planilhas demonstrativas dos estágios de $\operatorname{Tanner}^{103} \mathrm{em}$ desenhos. Adotou-se a classificação proposta pela Organização Mundial da Saúde $^{98}$ para agrupar os participantes entre pré-púberes e púberes. Para tanto, foram utilizados somente os dados relativos ao desenvolvimento de mamas no sexo feminino e da genitália no sexo masculino. O atraso puberal pode ser definido como ausência de caracteres sexuais secundários por volta de 13 anos e 4 meses em meninas, e 13 anos e 8 meses em meninos $^{104}$. Para a população brasileira, consideramos atraso puberal a ausência do desenvolvimento mamário (estágio 2) em meninas aos 13 anos ou a ausência de desenvolvimento genital no sexo masculino aos 14 anos (estágio 3), independente da presença ou não de pêlos pubianos ou axilares. 


\subsubsection{Consumo Alimentar}

A avaliação da ingestão alimentar foi realizada através de diário alimentar de 7 dias $^{99}$ precedentes à consulta, preenchido pelo próprio paciente ou responsável e revisado no momento do recebimento do mesmo, para minimizar possíveis erros de preenchimento. Para facilitar a compreensão do preenchimento do diário alimentar, foi demonstrado um exemplo de dieta com todos os itens a serem considerados (horário e tipo de refeição, variações dos alimentos e quantidades).

As variáveis quantitativas estudadas foram o valor calórico total da dieta (VCT), o consumo de macronutrientes (carboidrato, proteína e lipídio), fibras e dos micronutrientes (vitaminas A, B12,C, D, E, ácido fólico, cálcio, ferro, potássio, magnésio, sódio e zinco). Os cálculos foram realizados através do programa DietPro ${ }^{\circledR}$.

Para o cálculo da necessidade energética estimada (NEE) de cada adolescente, foram utilizadas as equações recomendadas pela ingestão diária recomendada $(\mathrm{DRI})^{107}$. O consumo energético (VCT) foi analisado considerando-se $100 \%$ da NEE e classificado em abaixo ou acima do recomendado. A ingestão de macronutrientes foi analisada de acordo com as recomendações da $\mathrm{WHO}_{\mathrm{FAO}}{ }^{108}$, sendo classificados em intervalos percentuais abaixo do limite inferior, acima do limite superior ou dentro do intervalo recomendado. Quanto aos micronutrientes, cada adolescente foi classificado, conforme seu consumo em abaixo ou acima do recomendado, considerando $100 \%$ da $\mathrm{DRI}^{107}$. 


\subsubsection{Parâmetros Bioquímicos}

Foram avaliados os níveis séricos de vitaminas A, B12, E, 25 Hidroxi vitamina D, ácido fólico e de ferro, cálcio iônico, zinco, magnésio, potássio, cobre e albumina de cada indivíduo no momento de sua inclusão no estudo.

Os valores obtidos foram analisados de acordo com os valores de referência adotados pelo Laboratório Central do HCFMUSP, exceto as dosagens das vitaminas A e E, que foram dosadas no Laboratório de Lípides (LIM 10) da FMUSP, segundo método de Arnaud ${ }^{109}$.

As técnicas utilizadas para as dosagens sangüíneas foram:

- Vitaminas A e E: cromatografia líquida de alta performance (HPLC);

- Ácido fólico, vitamina B12: quimioluminescência;

- 25 OHD: radioimunoensaio diasorin;

- Cálcio, ferro, albumina: colorimétrico automatizado;

- Ferritina: imunoturbidimétrico;

- Potássio: eletrodo íon específico;

- Cobre, zinco e selênio: espectrofotometria de absorção atômica;

- Magnésio: magon sulfonado;

- Fósforo: enzimático colorimétrico automatizado. 


\subsection{Análise estatística}

O teste Qui-quadrado $\left(X^{2}\right)$ foi utilizado com o objetivo de explorar as possíveis associações entre todas as variáveis e os três grupos (remissão, doença ativa e grupo controle). Foi fixado um nível de significância de $5 \%(p=0,05)$.

O processamento dos dados de consumo alimentar foi efetuado pelo software Dietpro, mas como haviam também alimentos e preparações que não faziam parte do banco de dados do software utilizado, estes alimentos foram comparados com a "Tabela de Composição de Alimentos para Suporte e Decisão Nutricional"110 e rótulos de alimentos regionais e locais. A análise dos dados foi realizada por meio dos programas Microsoft Excel, EpiInfo (versão 6.04) e SPSS (versão 13.0).

O presente estudo foi aprovado pelo Comitê de Ética em Pesquisa (CEP) da Faculdade de Medicina da Universidade de São Paulo. Os pais ou responsáveis pelos adolescentes convidados para participar do presente projeto, assinaram um termo de consentimento (Anexo A) concordando com a participação dos jovens no estudo. Em contrapartida, os participantes (pacientes e controles) receberam a avaliação nutricional, com a detecção e correção dos desvios nutricionais no ambulatório de Gastroenterologia do HCFMUSP. 
4 RESULTADOS 
Fizeram parte deste estudo 86 indivíduos, sendo 22 com DC em atividade leve ou moderada, 29 com DC em remissão e 35 controles.

As descrições sociodemográficas da amostra estão resumidos na Tabela 6.

Tabela 6 - Características sociodemográficas dos pacientes com doença de Crohn e do grupo controle

\begin{tabular}{|c|c|c|c|c|c|c|}
\hline & $\begin{array}{c}\mathrm{DC} \text { em } \\
\text { atividade (I) }\end{array}$ & $\begin{array}{c}\text { DC remissão } \\
\text { (II) }\end{array}$ & $\begin{array}{c}\text { Grupo } \\
\text { Controle } \\
\text { (III) }\end{array}$ & P1 & $\mathbf{P 2}$ & P3 \\
\hline Idade (anos) $\pm D P$ & $16,4 \pm 2,5$ & $17,3 \pm 2,19$ & $15,5 \pm 2,31$ & NS & NS & NS \\
\hline \multicolumn{7}{|l|}{ Sexo (\%) } \\
\hline Masculino & 54,5 & 55,2 & 62,8 & NS & NS & NS \\
\hline Feminino & 45,5 & 44,8 & 37,2 & NS & NS & NS \\
\hline \multicolumn{7}{|l|}{ Etnia (\%) } \\
\hline Branca & 90,9 & 89,6 & 91,3 & NS & NS & NS \\
\hline Não branca & 9,1 & 10,4 & 8,7 & NS & NS & NS \\
\hline
\end{tabular}

p1 = I versus II; p2 = I versus III; p3 = II versus III

NS = não significativa

Na Tabela 7 podemos observar que a idade média de início dos sintomas foi maior no grupo DC remissão, enquanto o diagnóstico foi mais tardio nos pacientes com doença em atividade. Os pacientes com DC em remissão apresentaram um maior tempo de diagnóstico da doença (média de 2,8 anos), porém, sem diferença significativa. 
Os pacientes com DC em atividade apresentaram maior presença de história familiar positiva do que os pacientes em remissão e passaram por mais procedimentos cirúrgicos.

Dos pacientes com DC em atividade, trës (13,6\%) passaram por procedimento cirúrgico, sendo duas ressecções ileais e uma colocação de sedanhos. Dentre os pacientes em remissão, somente um colocou sedanhos.

A Tabela 7 mostra as características clínicas dos pacientes estudados.

Tabela 7 - Dados clínicos dos pacientes com doença de Crohn
DC em atividade
DC remissão
P1

\begin{tabular}{|c|c|c|c|}
\hline $\begin{array}{l}\text { Tempo médio de duração } \\
\text { da doença (anos) } \pm D P\end{array}$ & $1,14 \pm 1,06$ & $2,83 \pm 3,34$ & NS \\
\hline $\begin{array}{l}\text { Idade média do início dos } \\
\text { sintomas (anos) } \pm \text { DP }\end{array}$ & $14,4 \pm 3,7$ & $14,1 \pm 3,7$ & NS \\
\hline $\begin{array}{l}\text { Idade média do } \\
\text { diagnóstico (anos)ะDP }\end{array}$ & $15,6 \pm 2,38$ & $14,5 \pm 3,66$ & NS \\
\hline História familiar de DC(\%) & 16,6 & 6,6 & * \\
\hline \multicolumn{4}{|l|}{ Cirurgia prévia (\%) } \\
\hline$-\operatorname{sim}$ & 13,6 & 3,4 & * \\
\hline - não & 86,4 & 96,6 & * \\
\hline \multicolumn{4}{|l|}{$\begin{array}{l}\text { Manifestações extra- } \\
\text { intestinais (\%) }\end{array}$} \\
\hline$-\operatorname{sim}$ & 40,9 & 44,8 & NS \\
\hline - não & 59,1 & 55,2 & NS \\
\hline
\end{tabular}

* $p<0,05 ;$ NS = não significativa 
Quanto à localização da doença, a maioria dos pacientes apresentou acometimento da região ileocólica, seguida pelas localizações ileal e colônica. Em relação ao comportamento da DC, as formas inflamatória e penetrante foram as mais frequentes (Tabela 8).

Tabela 8 - Localização e comportamento da doença nos pacientes com doença de Crohn

\section{DC em atividade (\%) $\quad$ DC em remissão (\%) $\quad$ P1}

\section{Localização}

- L1 (ileal)

- L2 (colônica)

- L3 (ileocólica)

- L4a

- L4b

Comportamento

- B1: inflamatório

- B2: estenosante

- B3: penetrante

- B2B3

- p: doença perianal modificada
36,3

13,6

50,1

0

0

37,9

24,1

38

0

0

Classificação de Paris $2010^{3}$
72,7

9,1

18,2

0

9,1
86,2

0

13,8

0

0
NS

NS

NS

NS

NS

NS

NS 
Na Tabela 9 estão listados os medicamentos em utilização pelos pacientes com DC. Todos os pacientes fizeram maior uso de azatioprina, principalmente com doença em atividade $(95,4 \%)$. No momento do trabalho, nenhum dos pacientes utilizava prednisona. Antibióticos (metronidazol e ciprofloxacina) foram empregados por cerca de um terço dos pacientes com DC em atividade e metade dos pacientes com DC em remissão. Quanto ao uso de infliximabe, $23 \%$ dos pacientes com DC em atividade utilizaram-no. Nenhum paciente utilizou adalimumabe.

Tabela 9 - Distribuição dos pacientes com doença de Crohn segundo a utilização de medicamentos atuais

\begin{tabular}{lccc}
\hline & DC em atividade (\%) & DC em remissão (\%) & $\mathbf{p}$ \\
\hline \hline Azatioprina & & & \\
Sim & 95,4 & 62,1 & $<0,005$ \\
Não & 4,6 & 37,9 & \\
Sulfassalazina & & & NS \\
Sim & 9,1 & 3,5 & \\
Não & 91,9 & 96,5 & NS \\
Mesalazina & & & \\
Sim & 45,4 & 55,2 & \\
Não & 54,6 & 44,8 & \\
Ciprofloxacina & & & \\
Sim & 13,6 & 41 & \\
Não & 86,4 & 59 & NS \\
Metronidazol & & & \\
Sim & 18,2 & 6,9 & NS \\
Não & 81,8 & 93,1 & \\
Infliximabe & & & \\
Sim & 23,1 & 82,8 & \\
Não & 76,9 & & \\
\hline
\end{tabular}


$\mathrm{Na}$ Tabela 10 estão listados os medicamentos previamente utilizados pelos pacientes com DC.

Tabela 10 - Distribuição dos pacientes com doença de Crohn segundo a utilização de medicamentos prévios

\begin{tabular}{lccc}
\hline & DC em atividade (\%) & DC em remissão (\%) & p \\
\hline \hline Azatioprina & 100 & 86,2 & NS \\
Sim & 0 & 13,8 & \\
Não & & & \\
Sulfassalazina & 13,6 & 10,3 & NS \\
Sim & 86,4 & 89,7 & \\
Não & & & \\
Prednisona & 90,9 & 51,7 & \\
Sim & 9,1 & 48,3 & NS \\
Não & & & \\
Ciprofloxacina & 54,5 & 55,2 & \\
Sim & 45,5 & 44,8 & NS \\
Não & & & \\
Metronidazol & 45,4 & 37,9 & NS \\
Sim & 54,6 & 62,1 & \\
Não & & & \\
Infliximabe & 36,3 & 20,7 & \\
Sim & 63,7 & 79,3 & \\
Não & & & \\
\hline
\end{tabular}

Como demonstrado na Tabela 11, a média do escore-z de estatura/idade e de IMC/idade aumentou progressivamente nos grupo DC em atividade, DC remissão e grupo controle respectivamente, mostrando diferença significativa entre os grupos. Quando comparados individualmente, 2 (9,1\%) pacientes com DC em atividade e 1 (3,4\%) em remissão apresentaram baixa estatura e $7(31,8 \%)$ pacientes com DC em atividade e 3 $(10,3 \%)$ em remissão estavam desnutridos. 
Observou-se um déficit mais proeminente de massa corporal magra, em relação ao compartimento de gordura corporal, nos pacientes com DC em atividade quando comparados com os outros 2 grupos.

Interessante notar que alguns pacientes apresentaram escore-z do IMC/ idade > 2 SDS, caracterizando sobrepeso em 4,2\% dos adolescentes com DC. Quanto ao estágio pubertário segundo Tanner, 22,7\% dos pacientes com DC em atividade e 6,9\% dos pacientes em remissão apresentaram um atraso puberal, mostrando diferença significativa entre esses dois grupos. Entre os pacientes do grupo controle, nenhum mostrou atraso puberal .

Tabela 11 - Avaliação antropométrica dos pacientes com DC em atividade, DC em remissão e do grupo controle

\begin{tabular}{|c|c|c|c|c|c|c|}
\hline & $\begin{array}{c}\text { DC em } \\
\text { atividade (I) }\end{array}$ & $\begin{array}{l}\text { DC em } \\
\text { remissão } \\
\text { (II) }\end{array}$ & $\begin{array}{c}\text { Grupo } \\
\text { Controle (III) }\end{array}$ & P1 & P2 & P3 \\
\hline z E/I & $-0,41 \pm 0,90$ & $-015 \pm 0,92$ & $0,24 \pm 0,99$ & * & * & * \\
\hline z IMC/I & $-1,29 \pm 1,64$ & $0,01 \pm 1,18$ & $0,37 \pm 1,18$ & * & * & * \\
\hline GC (\%)BIA) & $23 \pm 0,08$ & $21 \pm 0,05$ & $24 \pm 0,04$ & NS & NS & NS \\
\hline MM(\%) (BIA) & $74 \pm 0,08$ & $79 \pm 0,05$ & $76 \pm 0,04$ & * & * & NS \\
\hline $\begin{array}{l}\text { Atraso Puberal } \\
\text { (Tanner) (\%) }\end{array}$ & 22,7 & 6,9 & - & * & * & NS \\
\hline
\end{tabular}

p1 = I versus II; p2 = I versus III; p3 = II versus III;

$\mathrm{E} / \mathrm{I}=$ estatura/idade; IMC/I = IMC/idade;

$\mathrm{GC}=$ gordura corporal; $\mathrm{MM}=$ massa muscular

${ }^{*} p<0,05 ; N S=$ não significativa 
O consumo de energia total foi abaixo do recomendado para $50 \%$ dos adolescentes com DC em atividade e somente $3,5 \%$ e $5,7 \%$ dos pacientes com DC em remissão e do grupo controle, respectivamente (Figura 2).

Entre os macronutrientes, obteve-se um consumo abaixo dos limites recomendados entre $9,1 \%$ dos adolescentes com DC em atividade e 5,7\% do grupo controle, não demonstrando diminuição nos pacientes com DC em remissão para carboidratos. Em relação às proteínas, o consumo entre os pacientes com DC em atividade foi muito abaixo do recomendado quando comparado com os demais grupos, $68,2 \%, 17,2 \%$ e $14,3 \%$, respectivamente. Quanto aos lipídios, também se observou um consumo abaixo do limite inferior da recomendação principalmente nos indivíduos com DC em atividade (18,2\%).

Todos os grupos apresentaram baixo consumo de fibras alimentares, principalmente os grupos de pacientes portadores de DC.

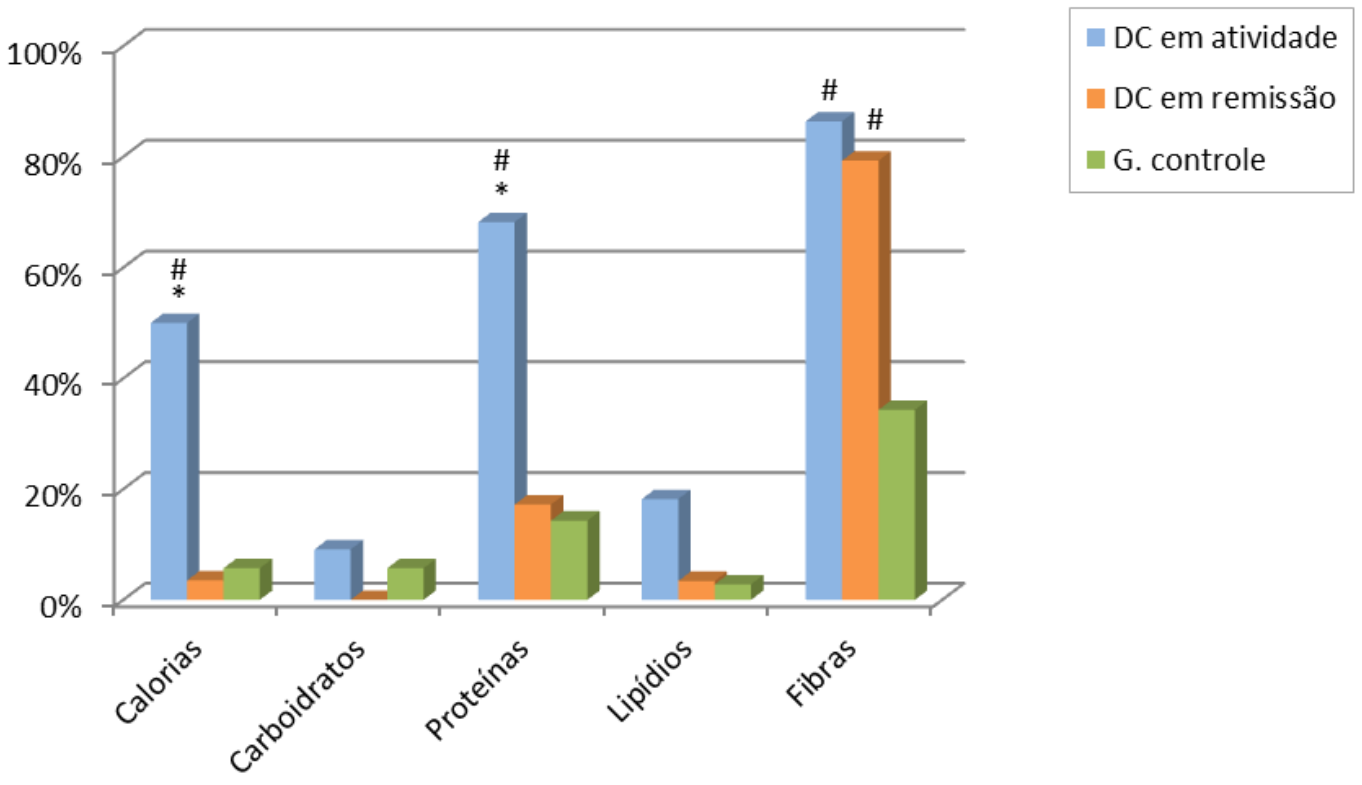

*p<0,05 em relação ao grupo DC remissão \# $p<0,05$ em relação ao grupo controle

Figura 2 - Percentual de deficiência na ingestão de calorias totais, macronutrientes e fibras nos pacientes com DC em atividade, DC em remissão e grupo controle 
Como podemos ver na Figura 3, a albumina sérica, mostrou-se mais deficiente nos pacientes com DC em relação ao grupo controle. O nível sérico de albumina foi menor nos pacientes em remissão e mostrou uma tendência de associação estatística significativa $(p<0,1)$ neste grupo em relação aos outros 2 grupos.

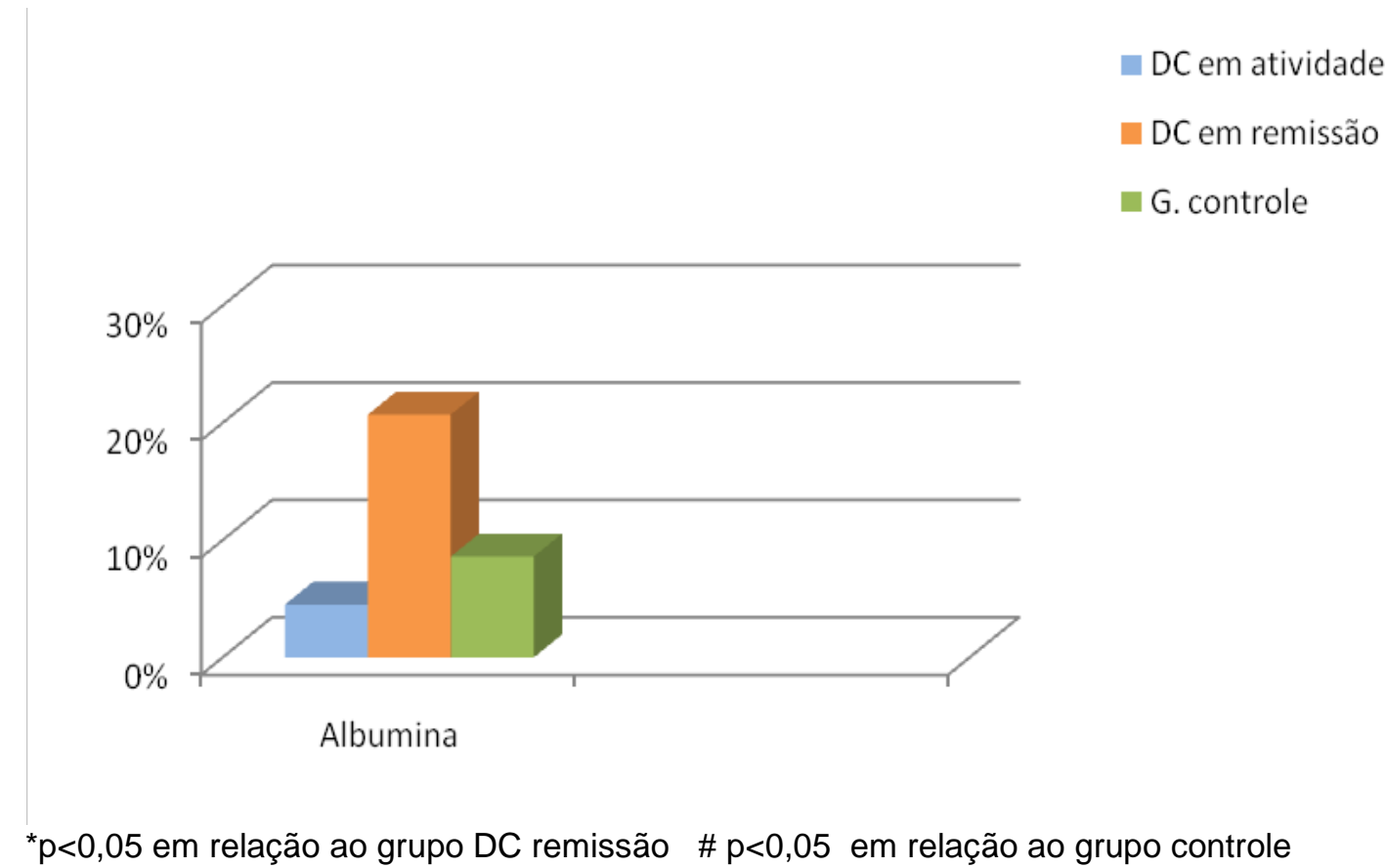

Figura 3 - Percentual de deficiência sérica de albumina nos pacientes com DC em atividade, DC em remissão e grupo controle 
A Figura 4 mostra a porcentagem de indivíduos com ingestão de minerais abaixo do recomendado. Todos os minerais avaliados no diário alimentar estavam deficientes.

Nos dados referentes ao cálcio, ferro, potássio, magnésio, selênio e zinco dietéticos o grupo DC atividade apresentou menor consumo, seguido pelo grupo DC remissão e grupo controle, respectivamente. Todos apresentaram diferença estatística significativa $(p<0,05)$.

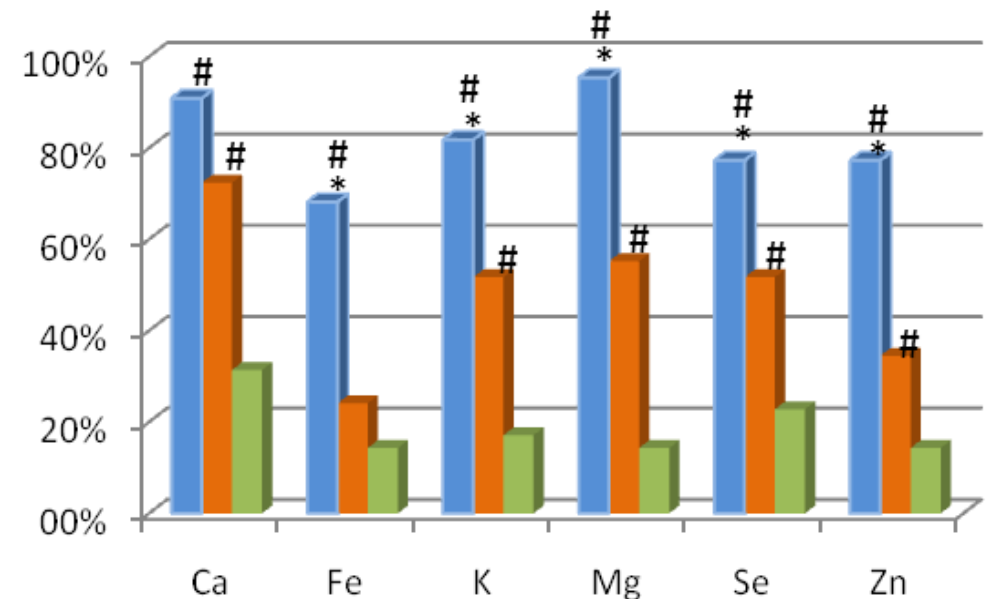

DC em atividade

DC em remissão

G. controle

* $p<0,05$ em relação ao grupo $D C$ remissão \# $p<0,05$ em relação ao grupo controle

Figura 4 - Percentual de deficiência na ingestão de minerais nos pacientes com DC em atividade, DC em remissão e grupo controle 
Como podemos observar na Figura 5, nenhum dos três grupos apresentou deficiência de cálcio e magnésio séricos, apesar da baixa ingestão vista na figura anterior.

O mineral estudado mais comumente encontrado com deficiência sérica foi o ferro $(p<0,05)$, e, diferentemente dos outros minerais, o grupo DC remissão mostrou-se mais deficiente que o grupo DC em atividade leve-moderada.

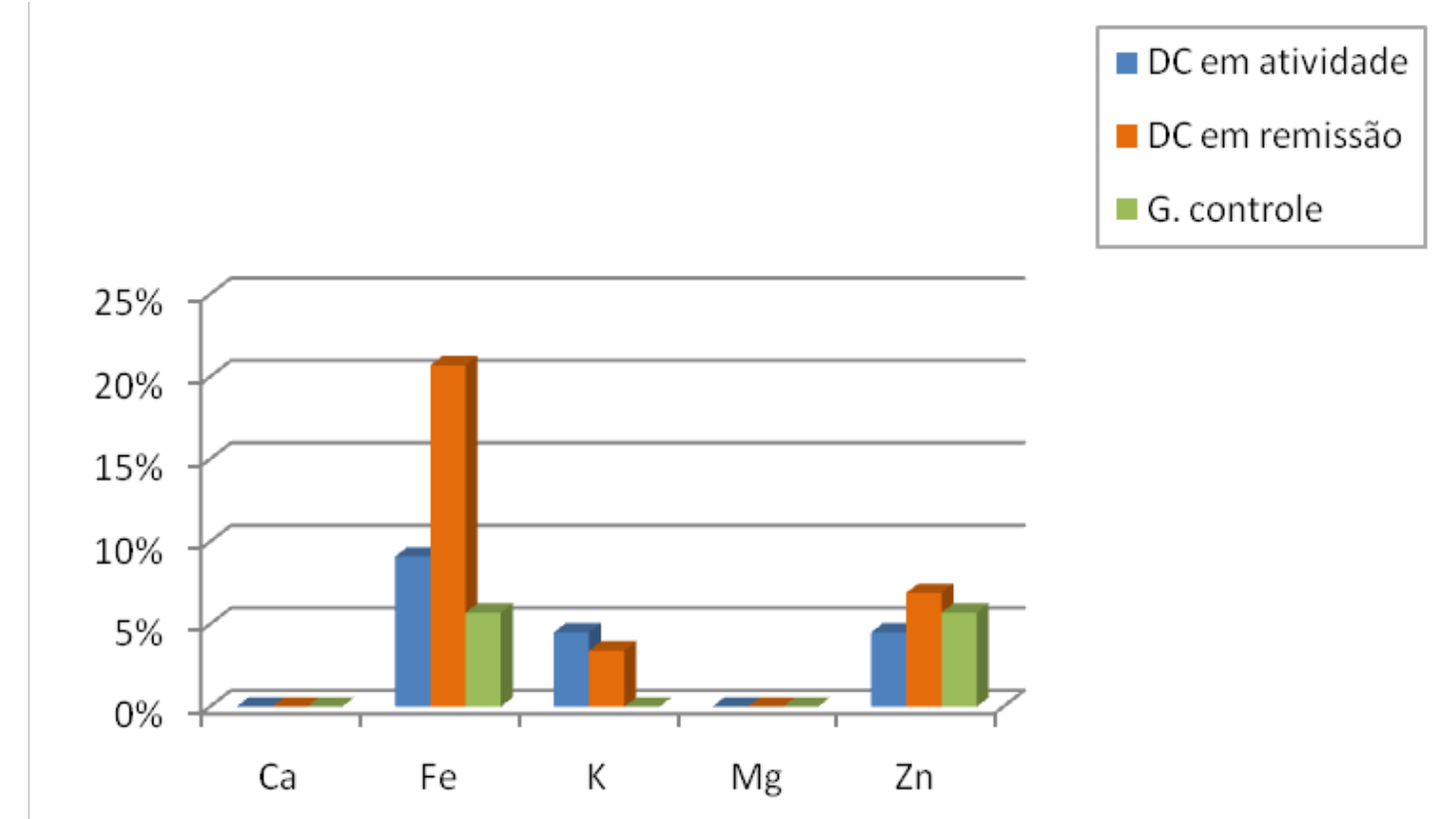

Figura 5 - Percentual de deficiência sérica de minerais nos pacientes com DC em atividade, DC em remissão e grupo controle 
Em relação às vitaminas, a Figura 6 nos mostra que o grupo DC em atividade apresentou consumo abaixo do recomendado em todas as vitaminas em, pelo menos, $75 \%$ de seus adolescentes.

Em todos estes nutrientes, os indivíduos com DC (em atividade seguida pela remissão) tiveram um menor consumo quando comparados ao grupo controle, havendo associação estatisticamente significativa $(p<0,05)$.

DC em atividade
DC em remissão
G. controle

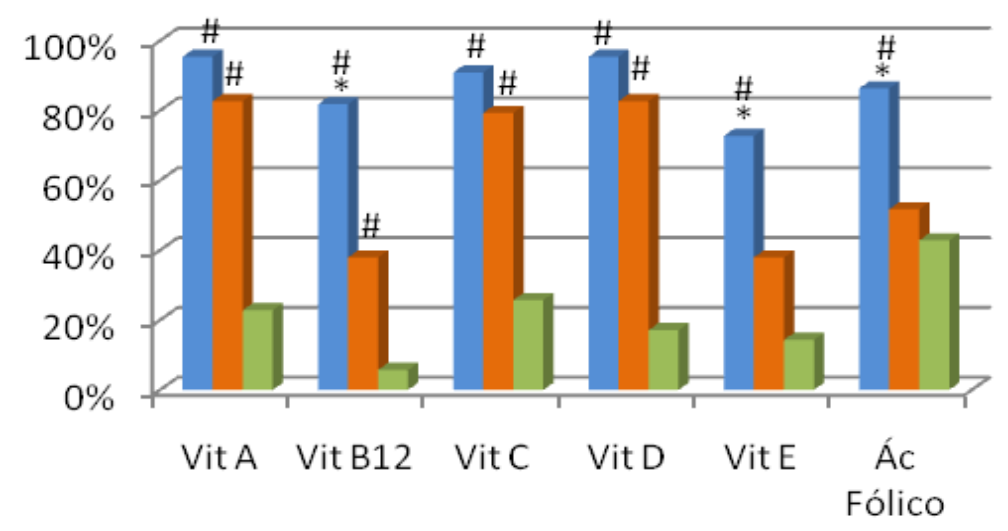

* $p<0,05$ em relação ao grupo $D C$ remissão \# $p<0,05$ em relação ao grupo controle

Figura 6 - Percentual de deficiência na ingestão de vitaminas nos pacientes com DC em atividade, DC em remissão e grupo controle 
Quando dosados no sangue, a vitamina D e o ácido fólico não se mostraram deficientes em nenhum dos grupos.

O grupo DC em atividade apresentou menores valores de vitaminas A e E em relação aos outros dois grupos $(p<0,05)$.

Em contrapartida, entre os grupos, o grupo DC remissão foi o de maior deficiência de vitamina B12, porém, não houve associação estatisticamente significativa $(p<0,05)$.

- DC em atividade
DC em remissão
G. controle

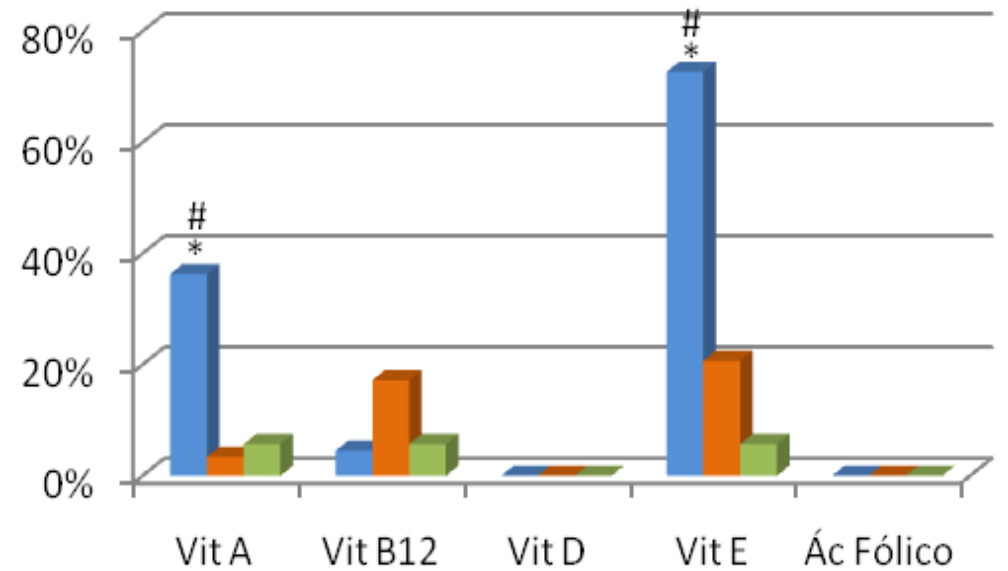

* $p<0,05$ em relação ao grupo DC remissão \# $\mathrm{p}<0,05$ em relação ao grupo controle

Figura 7 - Deficiência sérica de vitaminas nos pacientes com DC em atividade, DC em remissão e grupo controle 
5 DISCUSSÃO 
Os dados já existentes na literatura nacional e internacional sobre o estado nutricional de pacientes adolescentes com DC são escassos e setoriais, abordando isoladamente ou o crescimento ou a deficiência de uma ou mais vitaminas e minerais, dificultando uma análise global do estado nutricional do adolescente portador de DC. Entretanto, a maioria dos estudos mostraram concordância da presença e da importância da mánutrição entre os adolescentes com DC.

Existem várias dificuldades na comparação entre os dados encontrados neste estudo e os da literatura, entre elas a variabilidade do tempo de evolução da doença, a localização, a gravidade e o tratamento utilizado.

Em vários parâmetros avaliados, os pacientes diferiram do grupo controle, mesmo estes sendo seus parentes de primeiro grau, a mesma faixa etária e a mesma realidade social. Os adolescentes do grupo com doença em atividade (leve e moderada) também mostraram, em quase todos os dados analisados, pior estado nutricional do que o grupo com doença em remissão.

Neste estudo, pudemos observar que houve uma associação significativa de diminuição de IMC e estatura para a idade dos pacientes com DC quando comparados com o grupo controle, concordando com os estudo de Burnham et $\mathrm{al}^{112}$, realizado com 104 crianças e adultos jovens com DC, avaliados, em média, 4 anos após o diagnóstico, como neste estudo. 
Em um trabalho que acompanhou pacientes nesta mesma faixa etária durante 15 anos, Ferguson et $\mathrm{al}^{87}$ relataram que, apesar de aproximadamente metade dos adolescentes com DC apresentarem déficit de estatura, a maior parte deles atingiu a estatura normal na idade adulta. No estudo em discussão, aproximadamente $10 \%$ dos pacientes com DC em atividade e $3 \%$ dos pacientes com DC em remissão apresentaram baixa estatura no momento do estudo.

Em outro estudo de Burnham et al $^{66}$ que avaliou os compartimentos corporais, massa magra e gordura, os resultados obtidos também foram semelhantes aos encontrados neste estudo, principalmente em relação à massa magra, com resultado significativamente menor nos indivíduos com DC do que no grupo controle, entretanto, a gordura e a albumina foram preservadas, achado consistente com a denominada caquexia inflamatória ${ }^{66}$.

Em estudo transversal, Thayu et $\mathrm{al}^{78}$, como no presente estudo, encontraram em uma amostra de 78 crianças e adolescentes com DC, alterações significativas no crescimento, desenvolvimento pubertário e composição corporal, especialmente com a diminuição de massa magra, no momento do diagnóstico, em relação ao grupo controle, não encontrando diferença entre os sexos. O déficit de massa magra persistiu durante a evolução dos pacientes.

No atual estudo, identificamos pacientes com diagnóstico de sobrepeso. Este achado também foi encontrado por outros autores ${ }^{64}$, que alertaram que este resultado, na época da admissão do paciente, não deve ser utilizado como critério de exclusão da possibilidade diagnóstica da DC. 
O atraso puberal foi observado, no presente estudo, em $22,7 \%$ dos pacientes com DC em atividade e $6,9 \%$ dos pacientes com DC em remissão. Thayu et $\mathrm{al}^{78}$ também obtiveram atraso puberal em $12 \%$ dos pacientes com DC em comparação ao grupo controle. Uma hipótese sugerida para este achado seria o comprometimento do estado nutricional não corrigido.

No estudo em discussão, $50 \%$ dos adolescentes com DC em atividade e somente $3,5 \%$ e $5,7 \%$ dos pacientes com DC em remissão e do grupo controle, respectivamente, apresentaram ingestão calórica abaixo do recomendado. Segundo Thomas et $\mathrm{al}^{104}$, durante a exacerbação da doença, o consumo calórico pode diminuir $20 \%$ do recomendado, com o déficit de energia podendo chegar a $400 \mathrm{Kcal}$ por dia.

O gasto energético basal (GEB) de adolescentes com DC não é diferente daqueles saudáveis; o aparente aumento no GEB é resultante da diminuição na massa magra ${ }^{104}$.

Aghdassi et $\mathrm{al}^{99}$, em estudo realizado avaliando a ingestão alimentar de adultos canadenses com DC não encontraram diminuição no consumo de carboidratos e lipídeos na grande maioria dos pacientes com DC. Em relação às proteínas, 18,7\% dos indivíduos consumiram níveis abaixo do recomendado. Em contraste, no presente estudo, foi detectada uma proporção significativamente maior de baixa ingestão de proteínas $(68,2 \%)$ dos pacientes com DC em atividade e níveis semelhantes nos pacientes $(17,2 \%)$ com DC em remissão. Houve concordância em relação ao baixo consumo de fibras tanto no estudo de Aghdassi et al $^{99}$ como no estudo em discussão, pois ambos apresentaram aproximadamente $85 \%$ dos pacientes 
com DC em atividade com baixa ingestão de fibras, correspondente ao dobro do déficit do grupo controle.

Estes mesmos autores mostraram que a média de ingestão de todos os micronutrientes, exceto a vitamina B12, estavam abaixo da recomendação da DRI. Da mesma forma, o estudo em discussão mostra que todos os micronutrientes apresentaram grande prevalência de deficiência no consumo alimentar dos adolescentes com DC quando comparados com o grupo controle. Os indivíduos com doença ativa mostraram menor consumo de todos os micronutrientes quando comparado aos pacientes com doença em remissão, provavelmente relacionado a diminuição da ingestão global dos alimentos devido à presença dos sintomas gastrointestinais, como diarréia, dor e desconforto abdominal.

De acordo com Green et $\mathrm{al}^{112}$, as deficiências na ingestão alimentar são devidas às grandes mudanças dos hábitos alimentares que ocorrem após o diagnóstico da doença de Crohn. Este estudo observou mudanças qualitativas nos hábitos alimentares dos pacientes pediátricos com DC, os quais evitavam principalmente leites e derivados e alimentos vegetais, devido ao alto teor de fibras, principalmente pelo medo de desencadear a crise da doença.

Aproximadamente $30 \%$ dos pacientes com DC em nosso estudo apresentou deficiência sérica de ferro, o que coincide com pelo menos outros dois estudos ${ }^{113,114}$. O fato que nos surpreendeu foi a maior prevalência de déficit de ferro nos pacientes em remissão.Uma possível 
explicação seria que muitos pacientes com DC em atividade recebiam suplemento de ferro, corrigindo assim um possível déficit de ferro.

Este estudo não mostrou deficiência de folato sérico em nenhum dos três grupos analisados, provavelmente pelo extenso uso de suplemento de ácido fólico de rotina. Já a vitamina B12 apresentou menor valor no grupo DC remissão, denotando que apesar da remissão da doença, a mucosa ileal continuava inflamada, sendo detectado que apenas $6,9 \%$ destes pacientes haviam recebido vitamina B12 intramuscular. Outros estudos encontraram grande variabilidade nas dosagens das vitaminas B12 e folato séricos em pacientes com DC (0 a 81\%) $)^{115}$. Estas deficiências podem ser resultantes de necessidade aumentada, ingestão alimentar diminuída, absorção comprometida ou o uso de agentes terapêuticos, principalmente compostos de sulfassalazina ${ }^{116}$.

Em nosso estudo, as vitaminas A e E apresentaram maior deficiência sérica, principalmente nos pacientes com DC em atividade $(p<0,05)$. Este dado corrobora com estudo de Bousvaros et $\mathrm{al}^{95}$ que relacionaram a deficiência destas vitaminas com a atividade da doença. Hoffenberg et al $^{96}$ também $^{2}$ encontraram alterações nos níveis plasmáticos de vitaminas antioxidantes nos pacientes com DC em relação aos adolescentes com $\mathrm{CU}$ e grupo controle. A deficiência encontrada pode ser devida à má absorção, baixa ingestão ou diretamente relacionada à DC. Independentemente da etiologia, a diminuição nas concentrações destas vitaminas circulantes sugerem um desequilíbrio nas defesas antioxidantes nos pacientes pediátricos com DC. 
Outros déficits de micronutrientes encontrados em pacientes adultos com DC recém diagnosticados foram: magnésio, zinco e cobre ${ }^{75,89,92,93}$. Em nosso estudo, não foi detectada deficiência de magnésio em nenhum adolescente, no entanto, foi observada deficiência de zinco em todos os grupos avaliados, de forma não significativa, embora com menor tendência no grupo remissão; e finalmente, o cobre teve maior déficit nos pacientes com DC quando comparados com o controle, mas sem significância estatística. 
6 CONCLUSÃO 
Podemos concluir que os grupos de adolescentes com DC avaliados no presente estudo, tanto em atividade como em remissão, apresentaram comprometimento do estado nutricional significativo em relação ao grupo controle, na maioria dos parâmetros avaliados, devendo-se estender o acompanhamento nutricional global a todos os pacientes adolescentes portadores de DC. 
7 ANEXOS 


\section{Hospital dAS CLÍNICAS}

da Faculdade de Medicina da UNIVERSidAdE de SÃo PaUlo

CaIXa Postal, 8091 - SÃo PaUlo - Brasil

TERMO DE CONSENTIMENTO LIVRE E ESCLARECIDO

(Instruções para preenchimento no verso)

\section{I - DADOS DE IDENTIFICAÇÃO DO SUJEITO DA PESQUISA OU RESPONSÁVEL LEGAL}

1. NOME DO PACIENTE

DOCUMENTO DE IDENTIDADE No : SEXO :.$M \square F$ DATA NASCIMENTO: .............. $\mathrm{N}^{\mathrm{O}}$ APTO:

BAIRRO:

CEP: TELEFONE: DDD CIDADE $\mathrm{N}^{\circ}$ ..)

2.RESPONSÁVEL LEGAL

NATUREZA (grau de parentesco, tutor, curador etc.) DOCUMENTO DE IDENTIDADE No : SEXO :.$M \square F$ DATA NASCIMENTO: ........................ ENDEREÇO BAIRRO: CEP: TELEFONE: DDD ( CIDADE APTO: $\mathrm{N}^{\mathrm{O}}$ .)

\section{II - DADOS SOBRE A PESQUISA CIENTÍFICA}

1. TítULO dO PROTOCOLO DE PESQUISA: Avaliação Clínico-Laboratorial do Estado Nutricional de Adolescentes Portadores de Doença de Crohn.

2. PESQUISADOR: Camila Ortiz Prospero Cavalcante Costa CARGO/FUNÇÃO: Nutricionista INSCRIÇÃO CONSELHO REGIONAL No 11983 UNIDADE DO HCFMUSP: Disciplina de Gastroenterologia Clínica

3. AVALIAÇÃO DO RISCO DA PESQUISA:

$$
\text { SEM RISCO } \quad \square \quad \text { RISCO MÍNIMO - RISCO MÉDIO }
$$

4.DURAÇÃO DA PESQUISA : aproximadamente 2 anos. 


\section{III - REGISTRO DAS EXPLICAÇÕES DO PESQUISADOR AO PACIENTE OU SEU REPRESENTANTE LEGAL SOBRE A PESQUISA CONSIGNANDO:}

1. justificativa e os objetivos da pesquisa: A Doença Inflamatória Intestinal (DII) é uma doença crônica que acomete todo o aparelho digestivo causando dor, diarréia e sangramento, e pode ainda provocar desnutrição e déficit de crescimento em pacientes adolescentes. Esses pacientes podem ainda ter várias deficiências de vitaminas e minerais. A causa da DII não é bem conhecida, mas sabe-se que é mais comum em pessoas que tenham algum familiar de primeiro grau com a mesma doença. Sabe-se que vários fatores influenciam o aparecimento da doença de Crohn, sendo um deles a predisposição genética (herança genética, passada de pai para filho através dos genes, que têm todas as informações sobre as características de cada pessoa). Existem várias alterações genéticas em estudo que podem ser responsáveis pelo aparecimento da doença de Crohn em algumas pessoas e que podem ser herdadas de acordo com a etnia (raça).Temos como objetivo avaliar possíveis distúrbios nutricionais e tentar correlacionar com a presença ou não de alterações nos genes relacionados com a Doença Inflamatória Intestinal na população brasileira comparando com as pessoas normais da população.

2. procedimentos que serão utilizados e propósitos, incluindo a identificação dos procedimentos que são experimentais: Você preencherá um questionário de consumo alimentar para avaliar se este está adequado. Serão medidos peso, estatura e pregas cutâneas para avaliar antropometricamente o seu estado nutricional. Será realizado um raio-x de punho para verificar a sua idade óssea. Será feita coleta de sangue para avaliar os macro e micronutrientes e para a pesquisa das alterações genéticas. Esses resultados e as informações obtidas serão utilizados sem identificação e somente para o atual estudo.

3. desconfortos e riscos esperados: os riscos são apenas aqueles da coleta de sangue - dor no local da picada e pequeno hematoma (mancha roxa).

4. benefícios que poderão ser obtidos :Os benefícios principais que poderão ser obtidos pelo paciente são a correção de qualquer distúrbio do estado nutricional e dos macro e micronutrientes.

5. procedimentos alternativos que possam ser vantajosos para o indivíduo: Correção de erros nutricionais com reposição de macro e micronutrientes.

\section{V - ESCLARECIMENTOS DADOS PELO PESQUISADOR SOBRE GARANTIAS DO SUJEITO DA PESQUISA CONSIGNANDO:}

1. acesso, a qualquer tempo, às informações sobre procedimentos, riscos e benefícios relacionados à pesquisa, inclusive para dirimir eventuais dúvidas: Você poderá terá acesso a qualquer momento de informações sobre procedimentos, riscos e benefícios relacionados à pesquisa e tirar qualquer outra dúvida que possa ter.

2. liberdade de retirar seu consentimento a qualquer momento e de deixar de participar do estudo, sem que isto traga prejuízo à continuidade da assistência: A qualquer momento você terá liberdade de retirar seu consentimento e deixar de participar do estudo sem que isso traga prejuízo à continuidade do tratamento. 
3. salvaguarda da confidencialidade, sigilo e privacidade: Todas as informações fornecidas pelo participante da pesquisa serão mantidas em completo sigilo, como também os seus exames laboratoriais.

4. disponibilidade de assistência no HCFMUSP, por eventuais danos à saúde, decorrentes da pesquisa: Independentemente de sua participação na pesquisa você sempre terá direito ao atendimento médico no HCFMUSP.

5. viabilidade de indenização por eventuais danos à saúde decorrentes da pesquisa: Não está prevista qualquer indenização adicional por danos à sua saúde, decorrentes desta pesquisa, sabendo também que essa pesquisa não envolve maiores riscos.

\section{INFORMAÇÕES DE NOMES, ENDEREÇOS E TELEFONES DOS RESPONSÁVEIS PELO ACOMPANHAMENTO DA PESQUISA, PARA CONTATO EM CASO DE INTERCORRÊNCIAS CLÍNICAS E REAÇÕES ADVERSAS.}

Qualquer dúvida ou intercorrência entrar em contato com a nutricionista Camila Ortiz Prospero Cavalcante Costa no endereço Rua Aureliano Coutinho, 338 ap 61, tels 3337-0122 ou 9596-9610. E.mail: caprospero@gmail.com

\section{VI - CONSENTIMENTO PÓS-ESCLARECIDO}

Declaro que, após convenientemente esclarecido pelo pesquisador e ter entendido o que me foi explicado, consinto em participar do presente Protocolo de Pesquisa

São Paulo,

de

de 2009

assinatura do sujeito da pesquisa ou responsável legal

assinatura do pesquisador 


\section{Anexo B. Classificação de Paris}

\begin{tabular}{|c|c|}
\hline Classificação de Paris & \\
\hline Idade do diagnostico & $\begin{array}{l}\text { A1a: } 0-<10 a \\
\text { A1b:10-<17a } \\
\text { A2: } 17-40 a \\
\text { A3: }>40 a\end{array}$ \\
\hline Localização & $\begin{array}{l}\text { L1: distal } 1 / 3 \text { do íleo } \pm \text { doença cecal limitada } \\
\text { L2:colönica } \\
\text { L3: ileocolönica } \\
\text { L4a:doença proximal superior ao ligamento de Treitz } \\
\text { L4b: doença distal superior ao ligamento de Treitz e } \\
\text { proximal a distal1/3 do íleo }\end{array}$ \\
\hline Comportamento & $\begin{array}{l}\text { B1: não estenosante-não penetrante } \\
\text { B2: estenosante } \\
\text { B3: penetrante } \\
\text { B2B3: estenosante e penetrante, concomitantes ou em } \\
\text { diferentes períodos } \\
\text { p:doença perianal modificada }\end{array}$ \\
\hline Crescimento & $\begin{array}{l}\mathrm{G}_{0} \text { : sem evidëncia de prejuízo no crescimento } \\
\mathrm{G}_{1} \text { : crescimento prejudicado }\end{array}$ \\
\hline
\end{tabular}


Anexo C: Índice de atividade da doença de Crohn pediátrica (PCDAI)

\begin{tabular}{|c|c|c|c|}
\hline & & Valor & \\
\hline Dor abdominal & $\begin{array}{l}\text { Sem dor } \\
\text { Leve, náo interfere nas atividades diárias } \\
\text { Moderada/grave, interfere nas atividades } \\
\text { diárias }\end{array}$ & $\begin{array}{c}0 \\
5 \\
10\end{array}$ & \\
\hline Evacuações/dia & $\begin{array}{l}0-1 \text { líquida, sem sangue } \\
<2 \text { semi-formadas + pouco sangue ou 2-5 } \\
\text { liq. } \\
>6 \text { liq com sangue ou diarréia noturna }\end{array}$ & $\begin{array}{c}0 \\
5 \\
10\end{array}$ & \\
\hline Estado geral & $\begin{array}{l}\text { Bom, sem limitações das atividades } \\
\text { Regular, alguma dificuldade nas atividades } \\
\text { Péssimo, frequente limitação das atividades }\end{array}$ & $\begin{array}{c}0 \\
5 \\
10\end{array}$ & \\
\hline Peso & $\begin{array}{l}\text { Ganho ou manutenção de peso } \\
\text { Perda de peso }<10 \% \\
\text { Perda de peso }>10 \%\end{array}$ & $\begin{array}{c}0 \\
5 \\
10\end{array}$ & \\
\hline $\begin{array}{l}\text { Estatura (no } \\
\text { diagnóstico) }\end{array}$ & $\begin{array}{l}<1 \text { decréscimo a partir do percentil anterior } \\
<1 \text { a }<2 \text { decréscimo de percentil anterior } \\
\text { Diminuição } \geq 2 \text { canais de percentil anterior }\end{array}$ & $\begin{array}{c}0 \\
5 \\
10\end{array}$ & \\
\hline $\begin{array}{l}\text { Velocidade de } \\
\text { crescimento }\end{array}$ & $\begin{array}{l}<-1 \text { desvio padrão } \\
-1 \text { a }<-2 \text { desvio padrão } \\
\geq-2 \text { desvio padrão }\end{array}$ & $\begin{array}{c}0 \\
5 \\
10\end{array}$ & \\
\hline Abdomen & $\begin{array}{l}\text { Sem massa } \\
\text { Massa sem contornos definidos } \\
\text { Massa com contornos definidos }\end{array}$ & $\begin{array}{c}0 \\
0 \\
5 \\
10\end{array}$ & \\
\hline Doença peri-retal & $\begin{array}{l}\text { Nenhum } \\
1 \text { fístula indolente, pouca drenagem, não } \\
\text { sensíveis } \\
\text { Fístula ativa, drenagem, sensibilidade ou } \\
\text { abscesso }\end{array}$ & $\begin{array}{r}0 \\
5 \\
10\end{array}$ & \\
\hline Extraintestinal & $\begin{array}{l}\text { Nenhuma } \\
1 \text { manifestação } \\
2 \text { ou mais manifestações }\end{array}$ & $\begin{array}{c}0 \\
5 \\
10 \\
\end{array}$ & \\
\hline \multicolumn{4}{|l|}{ Laboratório } \\
\hline $\begin{array}{l}\text { Hematócrito (\%) } \\
\text { M:masculino } \\
\text { F: feminino }\end{array}$ & $\begin{array}{l}\text { M / F 6-10 anos: } \geq 33 \\
\text { M 11-14 anos: } \geq 35 \\
\text { 11-19 anos F: } \geq 34 \\
\text { M 15-19 anos: } \geq 37 \\
\text { M / F 6-10 anos: } 28-32 \\
\text { M 11-14 anos: } 30-34 \\
\text { F 11-19 anos: } 29-33 \\
\text { M 15-19 anos: } 32-36 \\
\text { M / F 60-10 anos: }<28 \\
\text { M 11-14 anos: }<30 \\
\text { F 11-19 anos: }<29 \\
\text { M 15-19 anos: }<32\end{array}$ & 2,5 & \\
\hline ESR & $\begin{array}{l}<20 \\
20-50 \\
>50\end{array}$ & $\begin{array}{c}0 \\
2,5 \\
5\end{array}$ & \\
\hline Albumina & $\begin{array}{l}\geq 35 \\
31-34 \\
\leq 30\end{array}$ & $\begin{array}{c}0 \\
5 \\
10\end{array}$ & \\
\hline
\end{tabular}

Classificação:

0-10: doença em remissão

10-30: doença leve

$>30$ : moderada a grave 


\section{Anexo D: Perfil dos pacientes}

\begin{tabular}{|c|c|c|c|c|c|c|c|c|c|c|c|c|c|}
\hline Paciente & Idade & Sexo & Localização & Comportamento & $\begin{array}{l}\text { Pcdai } \\
\text { Atual }\end{array}$ & $\begin{array}{c}\text { Ativ. } \\
\text { Pregressa }\end{array}$ & Cirurgias & $\begin{array}{c}\text { Idade inicio } \\
\text { dos sintomas } \\
\text { (anos) }\end{array}$ & $\begin{array}{c}\text { Idade do } \\
\text { diagnóstico } \\
\text { (anos) }\end{array}$ & $\begin{array}{c}\text { Tempo de } \\
\text { duração da } \\
\text { doença }\end{array}$ & $\begin{array}{l}\text { z-escore } \\
\text { estat/id }\end{array}$ & $\begin{array}{l}\text { z-escore } \\
\text { IMC/id }\end{array}$ & TANNER \\
\hline AMC & 18,6 & $\mathrm{~F}$ & Ileal & inflamatório & $<10$ & leve & $\mathrm{N}$ & 15 & 15 & 3,6 & $-2,07$ & $-1,17$ & M5P5 \\
\hline$A R$ & 18,8 & $\mathrm{M}$ & Ileal & estenosante & $<10$ & moderada & $\mathrm{N}$ & 10 & 11 & 7,7 & 0,36 & $-1,13$ & P4G4 \\
\hline CC & 18,9 & M & Ileal & inflamatório & $<10$ & leve & $\mathrm{N}$ & 6,33 & 6,58 & 12,3 & 0,2 & $-1,21$ & P5G5 \\
\hline GMR & 18 & $\mathrm{~F}$ & Colônica & inflamatório & $<10$ & grave & $\mathrm{N}$ & 16,58 & 16,58 & 1,4 & $-0,77$ & $-0,83$ & P3M4 \\
\hline$J R$ & 15,3 & $\mathrm{~F}$ & Ileal & inflamatório & $<10$ & moderada & $\mathrm{N}$ & 11,08 & 11,25 & 4 & $-0,28$ & 0,81 & P4G2 \\
\hline KCS & 18,9 & $\mathrm{M}$ & ileocolônica & inflamatório & $<10$ & leve & $\mathrm{N}$ & 18,5 & 18,5 & 0,4 & 0,61 & 1,7 & P4M4 \\
\hline LLF & 18,7 & $\mathrm{~F}$ & ileocolônica & inflamatório & $<10$ & leve & $\mathrm{N}$ & 17,16 & 17,16 & 1,6 & $-1,4$ & $-0,94$ & M4P4 \\
\hline MDFS & 17,4 & $\mathrm{~F}$ & Colônica & inflamatório & $<10$ & moderada & $\mathrm{N}$ & 16,42 & 16,58 & 0,9 & 0,48 & $-0,71$ & P5G5 \\
\hline MEV & 18,9 & $\mathrm{~F}$ & Íleal & estenosante & $<10$ & leve & $\mathrm{N}$ & 16,42 & 16,75 & 2,1 & 0,14 & $-0,74$ & P3G3 \\
\hline NBD & 18,2 & $\mathrm{~F}$ & Colônica & inflamatório & $<10$ & grave & $\mathrm{N}$ & 4,66 & 5 & 13,2 & $-1,09$ & $-0,62$ & P4M3 \\
\hline PPCMS & 16,3 & $\mathrm{M}$ & ileocolônica & inflamatório & $<10$ & grave & $\mathrm{N}$ & 8,75 & 8,83 & 7,7 & 1,21 & 2,15 & P3M4 \\
\hline RJG & 18,9 & $\mathrm{M}$ & ileal & fistulizante & $<10$ & leve & $\mathrm{N}$ & 16,5 & 18,08 & 0,8 & $-1,8$ & $-0,48$ & P5M5 \\
\hline $\mathrm{RLC}$ & 18,8 & $\mathrm{M}$ & ileal & inflamatório & $<10$ & leve & $\mathrm{N}$ & 18,08 & 18,66 & 0,1 & $-1,7$ & 0,99 & P4G4 \\
\hline VO & 18,9 & $\mathrm{M}$ & colônica & inflamatório & $<10$ & leve & $\mathrm{N}$ & 18 & 18,33 & 0,6 & $-0,86$ & $-0,15$ & P5G5 \\
\hline MVCM & 16,6 & $M$ & ileal & fistulizante & $<10$ & leve & $\mathrm{N}$ & 15,5 & 15,66 & 1 & $-0,42$ & 0,62 & P3G3 \\
\hline FVR & 18,7 & $\mathrm{M}$ & ileocolônica & inflamatório & $<10$ & leve & $\mathrm{N}$ & 12,16 & 16 & 2,7 & 0,78 & $-0,44$ & P3G4 \\
\hline CHNV & 18,7 & $M$ & ileocolônica & inflamatório & $<10$ & leve & $\mathrm{N}$ & 14,08 & 14,25 & 4,5 & $-0,74$ & 1,47 & P5G5 \\
\hline MOG & 12,4 & $\mathrm{~F}$ & ileocolônica & inflamatório & $<10$ & moderada & sedanhos & 9,42 & 9,58 & 3 & 1,19 & $-1,63$ & P4G4 \\
\hline DCC & 18,7 & $\mathrm{~F}$ & colônica & inflamatório & $<10$ & leve & $\mathrm{N}$ & 17,75 & 18 & 0,7 & $-0,02$ & $-0,63$ & P4G5 \\
\hline GCS & 17,6 & $M$ & íleocolônica & inflamatório & $<10$ & leve & $\mathrm{N}$ & 14,66 & 14,91 & 2,6 & $-0,37$ & $-1,48$ & $\mathrm{P} 2 \mathrm{M} 1$ \\
\hline JRD & 18,5 & $\mathrm{M}$ & ileal & inflamatório & $<10$ & leve & $\mathrm{N}$ & 17,08 & 17,41 & 1,1 & 0,35 & 2,37 & P4G4 \\
\hline ICPAA & 16,3 & $\mathrm{~F}$ & colônica & inflamatório & $<10$ & leve & $\mathrm{N}$ & 14 & 14,25 & 2 & 0,8 & $-0,19$ & P5G5 \\
\hline GAP & 12,9 & $\mathrm{M}$ & ileocolônica & inflamatório & $<10$ & leve & $\mathrm{N}$ & 10,33 & 12,5 & 0,4 & $-1,19$ & 1,48 & M3G4 \\
\hline RP & 18,7 & $\mathrm{M}$ & ileal & inflamatório & $<10$ & leve & $\mathrm{N}$ & 17,5 & 18 & 0,7 & 0,07 & 2,08 & M1G1 \\
\hline $\mathrm{MM}$ & 18,9 & $M$ & colônica & inflamatório & $<10$ & moderada & $\mathrm{N}$ & 16,16 & 16,41 & 2,5 & 0,9 & 0,32 & P4G5 \\
\hline RF & 16,2 & $\mathrm{~F}$ & ileal & fistulizante & $<10$ & moderada & $\mathrm{N}$ & 13,16 & 13,25 & 3 & 0,38 & $-0,59$ & M1G1 \\
\hline TZ & 16,2 & $\mathrm{~F}$ & íleocolônica & fistulizante & $<10$ & leve & $\mathrm{N}$ & 14 & 14,5 & 1,7 & $-0,26$ & $-1,26$ & P4G5 \\
\hline LAP & 18,6 & $\mathrm{~F}$ & íleocolônica & fistulizante & $<10$ & leve & $\mathrm{N}$ & 17,33 & 17,33 & 1,3 & 0,86 & 0,36 & M5P5 \\
\hline PHBG & 12,5 & $M$ & ileocolônica & estenosante & $<10$ & leve & $\mathrm{N}$ & 11,75 & 11,83 & 0,7 & 0,34 & 0,1 & G2P1 \\
\hline
\end{tabular}


PACIENTES EM ATIVIDADE

\begin{tabular}{|c|c|c|c|c|c|c|c|c|c|c|c|c|c|}
\hline Paciente & Idade & Sexo & Localização & Comportamento & $\begin{array}{l}\text { Pcdai } \\
\text { Atual }\end{array}$ & $\begin{array}{c}\text { Ativ. } \\
\text { Pregressa }\end{array}$ & Cirurgias & $\begin{array}{l}\text { Idade inicio } \\
\text { dos sintomas } \\
\text { (anos) }\end{array}$ & $\begin{array}{l}\text { Idade do } \\
\text { diagnóstico } \\
\text { (anos) }\end{array}$ & $\begin{array}{c}\text { Tempo de } \\
\text { duração da } \\
\text { doença }\end{array}$ & $\begin{array}{l}\text { z-escore } \\
\text { estat/id }\end{array}$ & $\begin{array}{l}\text { z-escore } \\
\text { IMC/id }\end{array}$ & TANNER \\
\hline$B C$ & 18,1 & $\mathrm{~F}$ & ileocolônica & inflamatória & $15(\mathrm{~L})$ & leve & $\mathrm{N}$ & 17,66 & 17,83 & 0,3 & $-0,48$ & 0,06 & M5G5 \\
\hline DFT & 12,2 & $\mathrm{M}$ & ileocolônica & inflamatória & $35(\mathrm{M})$ & moderada & $\mathrm{N}$ & 10 & 10,2 & 2 & $-2,1$ & $-3,2$ & P5G5 \\
\hline ERS & 17,1 & $\mathrm{~F}$ & colônica & inflamatória & $38(\mathrm{M})$ & grave & $\mathrm{N}$ & 15,25 & 15,5 & 1,6 & $-1,18$ & $-1,06$ & P5M5 \\
\hline EFRS & 15,3 & $M$ & ileal & fistulizante & $22(\mathrm{~L})$ & moderada & $\mathrm{N}$ & 14,16 & 14,25 & 1 & $-1,64$ & 1,05 & $\mathrm{P} 2 \mathrm{G} 1$ \\
\hline JDS & 18,2 & $\mathrm{~F}$ & colônica & inflamatória & $18(\mathrm{~L})$ & moderada & $\mathrm{N}$ & 17,33 & 17,5 & 0,7 & $-0,47$ & $-1,15$ & P5M5 \\
\hline MR & 18,9 & $M$ & ileocolônica & inflamatória & $23(L)$ & moderada & $\mathrm{N}$ & 13 & 13,33 & 5,6 & $-1,85$ & 0,04 & P5G4 \\
\hline MAV & 12,2 & $M$ & ileal & fistulizante & $33(\mathrm{M})$ & grave & sedanhos & 10,4 & 11,3 & 0,9 & $-0,59$ & 0,94 & P5M5 \\
\hline $\mathrm{MO}$ & 16,5 & $\mathrm{~F}$ & ileocolônica & inflamatória & $36(\mathrm{M})$ & grave & $\mathrm{N}$ & 16,16 & 16,25 & 0,3 & $-0,05$ & 0,02 & P3M4 \\
\hline YN & 17,6 & $M$ & ileal & inflamatória & $23(\mathrm{~L})$ & moderada & $\mathrm{N}$ & 16,16 & 16,41 & 1,2 & $-0,68$ & $-1,69$ & P5M5 \\
\hline VMM & 14,9 & $\mathrm{~F}$ & ileocolônica & fistulizante & $38(\mathrm{M})$ & moderada & $\mathrm{N}$ & 14,16 & 14,66 & 0,3 & 0,91 & 0,18 & P5M5 \\
\hline YBC & 17,9 & $M$ & ileal & estenosante & $34(\mathrm{M})$ & grave & ressecção do íleo & 17,58 & 17,75 & 0,1 & 0,39 & $-2,13$ & M4G4 \\
\hline MON & 18,8 & M & ileal & inflamatória & $38(\mathrm{M})$ & moderada & $\mathrm{N}$ & 16,25 & 16,33 & 2,5 & $-0,33$ & $-4,28$ & P5G4 \\
\hline FAR & 18,7 & $M$ & colônica & inflamatória & $26(\mathrm{~L})$ & moderada & $\mathrm{N}$ & 12,25 & 13,08 & 5,6 & 1,03 & 1,24 & P5M5 \\
\hline VAG & 15,9 & $\mathrm{~F}$ & ileocolônica & inflamatória & $22(\mathrm{~L})$ & leve & $\mathrm{N}$ & 15,33 & 15,66 & 0,2 & $-1,5$ & $-2,31$ & P5G4 \\
\hline$M G$ & 14,7 & $\mathrm{~F}$ & ileocolônica & fistulizante & $25(\mathrm{~L})$ & moderada & $\mathrm{N}$ & 4 & 14,25 & 0,5 & 0,52 & $-1,25$ & M1G2 \\
\hline EM & 18,5 & $\mathrm{~F}$ & ileal & inflamatória & 39(M) & grave & $\mathrm{N}$ & 8 & 18,5 & 0 & $-0,32$ & $-3,8$ & P3G3 \\
\hline $\mathrm{RR}$ & 17,8 & $M$ & ileal & estenosante & $42(\mathrm{M})$ & grave & ressecção do íleo & 17,58 & 17,75 & 0 & 0,1 & $-2,25$ & M1G2 \\
\hline $\mathrm{LJ}$ & 12,3 & $\mathrm{~F}$ & ileocolônica & inflamatória & $33(\mathrm{M})$ & moderada & $\mathrm{N}$ & 10,08 & 10,25 & 2 & $-2,33$ & $-1,09$ & P3G4 \\
\hline FRSN & 18,9 & $M$ & ileocolônica & inflamatória & $36(\mathrm{M})$ & grave & $\mathrm{N}$ & 18,66 & 18,91 & 0 & $-0,21$ & $-0,99$ & G5P4 \\
\hline GSP & 15,7 & $\mathrm{M}$ & ileocolônica & inflamatória & $25(\mathrm{~L})$ & moderada & $\mathrm{N}$ & 15,5 & 15,66 & 0 & 0,39 & $-2,13$ & M4G4 \\
\hline MRJ & 18,7 & $M$ & ileal & inflamatória & 19(M) & leve & $\mathrm{N}$ & 17,58 & 17,75 & 1 & 0,78 & $-0,44$ & P3G4 \\
\hline LBF & 14 & $\mathrm{~F}$ & ileocolônica & inflamatória & $22(\mathrm{~L})$ & moderada & $\mathrm{N}$ & 12,16 & 12,6 & 1,4 & $-0,33$ & $-4,28$ & P5G4 \\
\hline
\end{tabular}




\section{REFERÊNCIAS}


1. IBD Working Group of the European Society for Paediatric Gastroenterology, Hepatology and Nutrition (ESPGHAN). Inflammatory Bowel Disease in Children and Adolescents: Recommendations for Diagnosis - The Porto Criteria. J Ped Gastroenterol Nutr 2005; 41:1-7.

2. Sands BE. Crohn's disease. In: Feldman: Sleisenger \& Fordtran's. Gastrointestinal and Liver Disease: pathophysiology, diagnosis and management. $7^{\text {th }}$ ed. Philadelphia: Saunders 2002.p.2005-38.

3. Levine A, Griffiths A, Markowitz J, Wilson DC, Turner D, Russell RK, Fell J, Ruemmele FM, Walters T, Sherlock M, Dubinsky M, Hyams JS. Pediatric modification of the Montreal classification for inflammatory bowel disease: The Paris classification. Inflamm Bowel Dis 2010,1-8.

4. NASPGHAN/CCFA Working Group.Differentiation Ulcerative Colitis from Crohn Disease in Children and Young Adults: Report of a Working Group of the North American Society for Pediatric Gastroenterology, Hepatology, and Nutrition and the Crohn's and Colitis Foundation of America. J Pediatr Gastroenterol Nutr 2007; 44:653-674.

5. Mamula P, Markowitz J, Baldassano RN. Pediatric Inflammatory Bowel Disease. New York: Springer, 2008.

6. Rodrigues M, Barbieri D. First Brazilian National Inquire about Inflammatory Bowel Disease in children and adolescents: Paulista Society of Pediatric Gastroenterology and Nutrition. Medimond International Proceedings. Paris (France) 2004:3-7, 577-584. 
7. Sauer CG, Kugathasan S. Pediatric Inflammatory Bowel Disease : Highlighting Pediatric Differences in IBD. Gastroenterol Clin N Am 2009; 38:611-628.

8. Barret JC, Hansoul S, Nicolae DL, et al. Genoma-wide association defines more than 30 distint susceptibility loci for Crohn's disease. Nat Genet 2008;40:955-62.

9. Kugathasan S, Baldassaro RN, Bradfield JP, et al. Loci on 20q13 and $21 q 22$ are associated with pediatric-onset inflammatory bowel disease. Nat Genet 2008;40:1211-5.

10. Thomas GA, Rhodes J, Green JT. Inflammatory Bowel Disease and smoking. Am J Gastroenterol 1999; 93:144-9.

11. Bunn SK, Bisset WM, Main MJC, Golden BE. Fecal calprotectin as a measure of disease activity in childhood inflammatory bowel disease. J Pediatr Gastroenterol Nutr 2001;32:171-7.

12. Bunn SK, Bisset WM, Main MJC, Gray ES, Olson S, Golden BE. Fecal calprotectin: validation as a non-invasive measure of bowel inflammation in childhood inflammatory bowel disease. J Pediatr Gastroenterol Nutr 2001; 33:14-22.

13. Von Roon AC, Karamountzos L, Purkayastha S, et al. Diagnostic precision of fecal calprotectin for inflammatory bowel disease and colorectal malignancy. Am J Gastroenterol 2007;102: 803-13.

14. Fagerberg UL, Lööf L, Myrdal U, et al. Colorectal inflammation is well predicted by fecal calprotectin in children with gastrointestinal symptoms. J Pediatr Gastroenterol Nutr 2005;40:450-5. 
15. Berni Canani R, Rapacciuolo L, Romano MT, et al. Diagnostic value of faecal calprotectin in pediatric gastroenterology clinical practice. Dig Liver Dis 2004;36:467-70.

16. Walker TR, Land ML, Kartashov A, et al. Fecal lactoferrin is a sensitive and specific marker of disease activity in children and young adults with inflammatory bowel disease. J Pediatr Gastroenterol Nutr 2007;44:414-22.

17. Desai D, Faubion WA, Sandborn WJ. Review article: biological activity markers in inflammatory bowel disease. Aliment Pharmacol Ther 2007; 25(3): 247-55.

18. Quail MA, Russell RK, Van Limbergen JE, et al. Fecal calprotectin complements routine laboratory investigations in diagnosing childhood inflammatory bowel disease. Inflamm Bowel Dis 2009;15(5):756-9.

19. Mashako MN, Cezard JP, Navarro J, et al. Crohn's disease lesions in the upper gastrointestinal tract: correlation between clinical, radiological, endoscopic, and histological features in adolescents and children. J Pediatr Gastroenterol Nutr 1989; 8: 442-6.

20. Abdullah BA, Gupta SK, Croffie JM, et al. The role of esophagogastroduodenoscopy in the initial evaluation of childhood inflammatory bowel disease: a 7-year study. J Pediatr Gastroenterol Nutr 2002;35:636-40.

21. Sharif F, McDermott M, Dillon $M$, et al. Focally enhanced gastritis in children with Crohn's disease and ulcerative colitis. Am J Gastroenterol 2002; 97:1415-20. 
22. Castellaneta SP, Afzal NA, Greenberg M, et al. Diagnostic role of upper gastrointestinal endoscopy in pediatric inflammatory bowel disease. JPGN 2004; 39:257-61.

23. Laghi A, Borrelli O, Paolantonio P, et al. Contrast enhanced magnetic resonance imaging of the terminal ileum in children with Crohn's disease. Gut 2003; 52:393-7.

24. Darbari A, Sena L, Argani P, et al. Gadolinium-enhanced magnetic resonance imaging: a useful radiological tool in diagnosing pediatric IBD. Inflamm Bowel Dis 2004;10:67-72.

25. Essary B, Kim J, Anupindi S, Katz JA, Nimkin K. Pelvic MRI in children with Crohn disease and suspected perianal involvement. Pediatr Radiol 2007; 37: 201-8.

26. Gaca AM, Jaffe TA, Delaney S, et al. Radiation doses from small-bowel follow-through and abdomen/pelvis MDCT in pediatric Crohn disease. Pediatr Radiol 2008;38:285-91.

27. Albert JG, Martiny F, Krummenerl A, et al. Diagnosis of small bowel Crohn's disease: a prospective comparison of capsuleendoscopy with magnetic resonance imaging and fluoroscopic enteroclysis. Gut 2005;54:1721-7.

28. Triester SL, Leighton JA, Leontiadis GI, et al. A meta-analysis of the yield of capsule endoscopy compared to other diagnostic modalities in patients with non-stricturing small bowel Crohn's disease. Am J Gastroenterol 2006;101:954-64.

29. Thomson M, Fritscher-Ravens A, Mylonaki M, et al. Wireless capsule endoscopy in children: a study to assess diagnostic yield in small bowel disease in pediatric patients. J Pediatr Gastroenterol Nutr 2007;44:192-7. 
30. Boureille A, Ignjatovic A, Aabaken L, et al, Organisation Mondial d'Endoscopie Digestif (OMED), European Crohn's and Colitis Organisation (ECCO). Role of small bowel endoscopy in the management of patients with IBD: an international OMEDECCO Consensus. Endoscopy 2009;41:618-37.

31. Anato B, Bishop J, Shawis R, Thomson M. Clinical application and diagnostic yield of wireless capsule endoscopy in children. $J$ Laparoendosc Adv Surg Tech, Part A 2007;17:364-70.

32. Fritscher-Ravens A, Scherbakov $P$, Bufler $P$ et al. The Feasibility of wireless capsule endoscopy in detecting small intestinal pathology in children under the age of 8 years Multicenter European Study. Gut 2009 Nov;58(11):1467-72.

33. Silverberg MS, Satsangi J, Ahmad T el al. Toward an integrated clinical, molecular and serologic classification on inflammatory bowel disease :report of Working Paty of the 2005 Montreal World Congress of Gastroenterol. Can J Gastroenterol 2005;19(suppl A):5-36.

34. Hyams JS, Ferry GD, Mandel FS, Gryboski JD, Kibort PM, Kirschner BS, et al. Development and validation of a pediatric Crohn's disease activity index. J Pediatr Gastroenterol Nutr 1991;12(4):439-47.

35. Turner D, Otley AR, Mack D, Hyams J, Bruijine J, Uusoue K, et al. Development, validation and evaluation of pediatric ulcerative colitis activity index: a prospective multicenter study. Gastroenterol 2007; 133:423-32.

36. Motil KJ, Grand RJ, Davis-Kraft L, Ferlic LL, Smith EO. Growth failure in children with inflammatory bowel disease: a prospective study. Gastroenterology 1993;105:681-91. 
37. Markowitz J, Grancher K, Rosa J, Aiges H, Daum F. Growth failure in pediatric inflammatory bowel disease. J Pediatr Gastroenterol Nutr 1993;16:373-80.

38. Stephens M, Batres LA, Ng D, Baldassano R. Growth failure in the child with inflammatory bowel disease. Semin Gastrointest Dis 2001;12:253-62.

39. Biancone L, Michetti P, Travis S et al. European Crohn's and Colitis Organisation (ECCO). European evidence-based Consensus on the management of ulcerative colitis: Special situations. J Crohn Colitis 2008, 2:67-84.

40. Van Assche G, Dignass A, Reinisch W et al. The second European evidence-based consensus on the diagnosis and managment of Crohn's disease: special situations. J Crohn's Colitis 2010; 4: 63-101.

41. Askling J, Grahnquist L, Ekbom A, Finkel Y. Incidence of paediatric Crohn's disease in Stockholm, Sweden. Lancet 1999; 354:1179.

42. Armitage E, Drummond HE, Wilson DC, Ghosh S. Increasing incidence of both juvenile-onset Crohn's disease and ulcerative colitis in Scotland. Eur J Gastroenterol Hepatol 2001;13:1439-47.

43. Urne FU, Paerregaard A. Chronic inflammatory bowel disease in children. An epidemiological study from eastern Denmark 1998- 2000 [in Danish]. Ugeskr Laeger 2002;164:5810-4.

44. Hildebrand $H$, Finkel $Y$, Grahnquist $L$, et al. Changing pattern of paediatric inflammatory bowel disease in northern Stockholm 19902001. Gut 2003;52:1432-4. 
45. Phavichitr N, Cameron DJ, Catto-Smith AG. Increasing incidence of Crohn's disease in Victorian children. J Gastroenterol Hepatol 2003;18:329-32.

46. Kolek A, Janout V, TichyM, GrepIM. The incidence of inflammatory bowel disease is increasing among children 15 years old and younger in the Czech Republic. J Pediatr Gastroenterol Nutr 2004;38:362-3.

47. Kugathasan S, Judd RH, Hoffmann RG, et al.Epidemiologic and clinical characteristics of children with newly diagnosed inflammatory bowel disease in Wisconsin: a statewide population-based study. J Pediatr 2003;143:525-31.

48. Van Limbergen J, Russel RK, Drummond HE et al. Definition of phenotypic characteristics of childhood-onset inflammatory bowel disease. Gastroenterology 2008;135:1114-22.

49. Vernier-Massouille G, Balde M, Salleron J, et al. Natural history of pediatric Crohn's disease: a population-based cohort study. Gastroenterology 2008;135:1106-13.

50. Sagiv-Friedgut, K; Karban, A; Weiss, B; Shaoul, R; Shamir, R; Bujanover, Y; Reif, S; Boaz, M; Shani, I; Levine, A; Leshinsky-Silver, E. Early-onset Crohn Disease Is Associated With Male Sex and a Polymorphism in the IL-6 Promoter. JPGN 2010, 50(1): 22-26.

51. Motil KJ, Grand RJ, Davis-Kraft L, Ferlic LL, Smith EO. Growth failure in children with inflammatory bowel disease: a prospective study. Gastroenterology 1993;105:681-91.

52. Sawczenko A, Sandhu BK. Presenting features of inflammatory bowel disease in Great Britain and Ireland. Arch Dis Child 2003;88:995-1000. 
53. Heuschkel R, Salvestrini C, Beattie RM, et al. Guidelines for management of growth failure in childhood inflammatory bowel disease. Inflamm Bowel Dis 2008;14:839-49.

54. Seidman E, LeLeiko N, Ament A et al. Nutritional issues in pediatric inflammatory bowel disease. JPGN 1991;12:424-438.

55. Ballinger AB, Camacho-Hubner C, Croft NM. Growth failure and intestinal inflammation. Q J Med 2001;94:121-125.

56. Mack DR, Langton C, Markowitz J et al. Laboratory values for children with newly diagnosed inflammatory bowel disease. Pediatrics 2007; 119(6):1113-9.

57. Dubinsky MC, Ofman JJ, Urman M, Targan SR, Seidman EG. Clinical utility of serodiagnostic testing in suspected pediatric inflammatory bowel disease. Am J Gastroenterol 2001;96:758-65.

58. Rodrigues M,Sipahi AM, Damião AO, Bueno C, Neufeld CB, Pinto EA et al. Multicentric study of serologic testing in inflammatory bowel disease in children and adolescents in Brazil. JPGN 2006;43(4):E54.

59. Gupta SK, Fitzgerald JF, Croft JM, Pfefferkorn MD, Molleston JP, Corkins MR. Comparison of serologic markers of inflammatory bowel disease with clinical diagnosis in children. Inflamm Bowel Dis 2004;10: 240-4.

60. Kanof ME, Lake AM, Bayless TM. Decreased height velocity in children and adolescents before the diagnosis of Crohn's disease. Gatroenterology 1988;95:1523-27. 
61. Kleinman RE, Baldassano E, Robert N, Caplan M, Griffiths AM, Heyman MB, Issenman RM Lake AM. Nutrition support for pediatric patients with inflammatory bowel disease: a clinical report of the North America Society for Pediatric Gastroenterology, Hepatology end Nutrition. JPGN 2004; 39(1):15-27.

62. Wiskin AE, Wooton SA, Beattie RM. Nutrition Issues in Pediatric Crohn's Disease. Nutr clin Pract 2007; 22: 214-222.

63. Razack R, Seidner DL. Nutrition in inflammatory bowel disease. Curr Opin Gastroenterol 2007;23:400-5.

64. Kugathasan S, Nebel J, Skelton JA et al. Body mass index in children with newly diagnosed inflammatory bowel disease: observations from two multicenter North American inception cohorts. J Pediatr 2007;151:523-7.

65. Weinstein TA, Levine M, Pettei MJ, Gold DM, Kessler BH, Levine JJ. Age and family history at presentation of pediatric inflammatory bowel disease. JPGN 2003;37:609-13.

66. Burnham JM, Shults J, Semeao E et al. Body-composition alterations consistent with cachexia in children and young adults with Crohn disease. Am J Clin Nutr 2005;82:413-20.

67. Jahnsen J, Falch JA, Mowinckel P, Aadland E. Body composition in patients with inflammatory bowel disease: a population-based study. Am J Gastroenterol 2003;98:1556-62.

68. Paerregaard A, Uldall UF. Anthropometry at the time of diagnosis in Danish children with inflammatory bowel disease. Acta Paediatr 2005;94:1682-3. 
69. Sousa GC, Cravo M, Costa AR et al. A comprehensive approach to evaluate nutritional status in Crohn's patients in the era of biologic therapy: a case-control study. Am J Gastroenterol 2007;102:2551-6.

70. Wells JC, Fewtrell MS. Measuring body composition. Arch Dis Child 2006;91:612-7.

71. Reilly JJ. Diagnostic accuracy of the BMI for age in paediatrics. Int $\mathrm{J}$ Obes (Lond) 2006;30:595-7.

72. Cole TJ, Freeman JV, Preece MA. Body mass index reference curves for the UK, 1990. Arch Dis Child 1995;73:25-9.

73. Capristo E, Mingrone G, Addolorato G, Greco AV, Gasbarrini G. Metabolic features of inflammatory bowel disease in a remission phase of the disease activity. J Intern Med 1998;243:339-47.

74. Ma K, Mallidis C, Bhasin S et al. Glucocorticoid-induced skeletal muscle atrophy is associated with upregulation of myostatin gene expression. Am J Physiol Endocrinol Metab 2003;285:E363-E371.

75. Geerling BJ, Badart-Smook A, Stockbrugger RW, Brummer RJ. Comprehensive nutritional status in patients with long-standing Crohn disease currently in remission. Am J Clin Nutr 1998;67:919-26.

76. Boot AM, Bouquet J, Krenning EP, de Muinck Keizer-Schrama SM. Bone mineral density and nutritional status in children with chronic inflammatory bowel disease. Gut 1998;42:188-94.

77. Sentongo TA, Semeao EJ, Piccoli DA, Stallings VA, Zemel BS. Growth, body composition, and nutritional status in children and adolescents with Crohn's disease. JPGN 2000;31:33-40. 
78. Thayu M, Shults J, Burnham JM, Zemel BS, Baldassano RN, Leonard MB. Gender differences in body composition deficits at diagnosis in children and adolescentes with Crohn's disease. Inflamm Bowel Dis 2007;13:1121-8.

79. Boot AM, Bouquet J, Krenning EP, de Muinck Keizer-Schrama SM. Bone mineral density and nutritional status in children with chronic inflammatory bowel disease. Gut 1998;42:188-94.

80. Kanoff ME, Lake AM, Bayless TM. Decreased height velocity in children and adolescents before the diagnosis of Crohn's disease. Gastroenterology 1988;95:1523-7.

81. Markowitz J, Daum F. Growth impairment in pediatric inflammatory bowel disease. Am J Gastroenterol 1994;89:319-26.

82. Hildebrand $\mathrm{H}$, Karlberg J, Kristiansson B. Longitudinal growth in children and adolescents with inflammatory bowel disease. JPGN 1994; 18:165-73.

83. Alemzadeh N, Rekers-Mombarg L, Mearin ML, Wit JM, Lamers CBHW, Hogezand RA. Adult height in patients with early onset of Crohn's disease. Gut 2002; 51:26-9.

84. Shamir R, Phillip M, Levine A. Growth Retardation in Pediatric Crohn's Disease: Pathogenesis and Interventions. Inflamm Bowel Dis 2007; 13(5):620-8.

85. Hyams JS, Carey DE. Corticosteroids and growth. J Pediatr 1988; 113:249-54.

86. [WHO] World Health Organization. Physical status: the use and interpretation of anthropometry. Geneva; 1995. 
87. Ferguson A, Sedgwick DM. Juvenile onset inflammatory bowel disease: height and body mass index in adult life. BMJ 1994;308:1259-63.

88. Levy E, Rizwan Y, Thibault L et al. Altered lipid profile, lipoprotein composition, and oxidant and antioxidant status in pediatric Crohn disease. Am J Clin Nutr 2000;71:807-15.

89. Wenland BE, Aghdassi E, Tam C et al. Lipid peroxidation and plasma antioxidant micronutrients in Crohn disease. Am J Clin Nutr 2001;74:259-64.

90. D'Odorico A, Bortolan S, Cardin R et al. Reduced plasma antioxidant concentrations and increased oxidative DNA damage in inflammatory bowel disease. Scand J Gastroenterol 2001;36:1289-94.

91. Phylactos AC, Fasoula IN, rnaud-Battandier F, Walker-Smith JA, Fell JM. Effect of enteral nutrition on antioxidant enzyme systems and inflammation in pediatric Crohn's disease. Acta Paediatr 2001;90:883-8.

92. Hengstermann S, Valentini L, Schaper L et al. Altered status of antioxidant vitamins and fatty acids in patients with inactive inflammatory bowel disease. Clin Nutr 2008;27:571-8.

93. Filippi J, Al-Jaouni R, Wiroth JB, Hebuterne X, Schneider SM. Nutritional deficiencies in patients with Crohn's disease in remission. Inflamm Bowel Dis 2006;12:185-91.

94. Fernandez-Banares F, bad-Lacruz A, Xiol X et al. Vitamin status in patients with inflammatory bowel disease. Am J Gastroenterol 1989;84:744-8.

95. Bousvaros A, Zurakowski D, Duggan $C$ et al. Vitamins $A$ and $E$ serum levels in children and young adults with inflammatory bowel disease: effect of disease activity. JPGN 1998;26:129-35. 
96. Hoffenberg EJ, Deutsch J, Smith S, Sokol RJ. Circulating antioxidant concentrations in children with inflammatory bowel disease. Am J Clin Nutr 1997;65:1482-8.

97. Tanner JM. Growth at adolescence. Oxford: Blackwell, 1962.

98. Wiskin AE, WoottonSA, Hunt TB, Cornelius VR, Afzal NA, Jackson AA, Beattie RM. Body composition in childhood inflammatory bowel disease. Clinical Nutrition 2010: 1-4.

99. Aghdassi E, Wendland BE, Stapleton M, Raman M, Allard JP. Adequacy of Nutritional Intake in a Canadian Population of Patients with Crohn's Disease. J Am Diet Assoc 2007; 107: 1575-1580.

100. Han PD, Burke A, Baldassano RN. Nutrition and inflammatory bowel disease. Gastroenterol Clin North Am 1999; 28: 423-443.

101. Slinde F, Rossander-Hulthen L. Bioelectrical impedance: effect of three identical meals on diurnal impedance variation and calculation of body composition. Am J Clin Nutr. 2001;74:474-8.

102. Bleil SI. O padrão alimentar ocidental: considerações sobre a mudança de hábitos no Brasil.Cad Debate 1998; 6(1): 1-24.

103. Branen L, Flecher J. Comparison os college students current eating habits and recollections of their childhood food practices. J Nutr Educ 1999; 31 (6): 304-309.

104. Thomas AG, Taylor F, Miller V. Dietary intake and nutritional treatment in childhood Crohn's disease. JPGN 1993;17:75-81. 
105. Onis $\mathrm{M}$ et al. Development of a WHO growth reference for school-aged children and adolescents. Bulletin of the World Health Organization. 2007, 85 (9). Available at: http://www.who.int/growthref/growthref who bull.pdf

106. Lohman TG. Assessment of body composition in children. Ped Exerc Sci. 1989; 1: 19-30.

107. Institute of Medicine. Dietary Reference Intakes for Individuals. Food and Nutrition Board. Washinghton, DC: National Academy Press; 2002.

108. World Health Organization. Diet, Nutrition and the Prevention of Chronic Diseases. Report of a joint WHO/FAO expert consultation. Geneva; 2003. [WHO Technical Report Series, 916].

109. Arnaud J, Fortis I, Balkier S, Kia D, Favier A. Simultaneous determination of retinol, alpha-tocopherol and beta-carotene in serum by isocratic high-performance liquid chromatography. J Chromatogr. 1991;572(1-2):103-16.

110. Philippi, S.T. Tabela de Composição de Alimentos: suporte para decisão nutricional. Brasília: Anvisa, Finatec/Nut-UnB; 2001.

111. Burnham JM, Schults J, Semeao E, Foster BJ, Zemel BJ, Stallings VA, Leonard MB. Whole body BMC in pediatric Crohn disease: independent effects of altered growth, maturation and body composition. $J$ Bone Miner Res 2004; 19: 1961-1968.

112. Green TJ, Issenman RM, Jacobson K. Patients diets and preferences in a pediatric population with inflammatory bowel disease. Can $J$ Gastroenterol 1998; 12(8): 544-549. 
113. Gasche C, Reinisch W, Lochs H. Anemia in Crohn's disease. Importance of inadequate erythropoietin production and iron deficiency. Dig Dis Sci 1994; 39: 1930-1934.

114. Oldenburg B, Koningsberger JC, Berge Henegouwen GP, Van Asbeck BS, Marx JJ. Iron and inflammatory bowel disease. Aliment Pharmacol Ther 2001; 15: 429-438.

115. Yakut M, Ustun Y, Kabaçam G, Soykan I. Serum vitamin B12 and folate status in patients with inflammatory bowel diseases. Eur J Int Med 2010;21: 320-323

116. Hoffbrand AV, Stewart JS, Booth CC, Mollin DL. Folate deficiency in Crohn's disease : incidence, pathogenesis and treatment. $\mathrm{Br}$ Med J 1968; 2:71-75. 